\title{
7. Estrategias pedagógicas: el punto de partida y la caja de herramientas para la adaptación, inducción y retención es- tudiantil en la modalidad virtual
}

\author{
Luis Martín Trujillo Flórez
}

\section{Introducción}

U no de los aspectos más relevantes al iniciar un proceso de aprendizaje es conocer qué tan preparados están los estudiantes para empezar. El sistema educativo colombiano habla del uso de las tecnologías de la información y de la comunicación (TIC), sin embargo, no prepara a los estudiantes para la modalidad virtualidad; son pocos los cursos en la educación media que perfilen al estudiante para una educación superior virtual. Esto acarrea que muchos estudiantes no estén preparados para el e-learning. Desde el punto de vista de Varón y Moreno (2009), así hablemos de autonomía, en las aulas ni los estudiantes ni los tutores actúan de manera autónoma.

Es común encontrar estudiantes con un fuerte arraigo por la calificación y enfocan sus esfuerzos para trabajar por una nota y no por un aprendizaje. Esto porque todavía no tienen claro su proceso como ser autónomo protagonista y responsable de su aprendizaje.

Por otro lado, se tiene la errónea creencia que lo único necesario para un aprendizaje mediado por tecnología es manejar herramientas de software, cuando este es solo uno de los pasos. La virtualidad le exige al individuo motivación, autonomía, hábitos de estudio, métodos de lectura y de resumen, manejo y búsqueda de la información, pensamiento analítico, interpretativo y creativo, manejo de las herramientas, entre otros. Con tales antecedentes, vale la pregunta que inicia este capítulo: ¿cuántos estudiantes tienen tales competencias para iniciar su proceso de aprendizaje?

Luis Martín Trujillo Flórez. Ingeniero eléctrico por la Universidad Nacional de Colombia, especialista en Entornos Virtuales de Aprendizaje por el Centro de Altos Estudios Universitarios y magíster en Edición Universitaria por la Universidad de Salamanca. Coordinador Pedagógico y de Innovación de Contenidos de Educación Virtual. e-mail: mtrujillo@poligran.edu.co 
De acuerdo con la experiencia que trabaja el Politécnico Grancolombiano, que cuenta con una población de 40000 estudiantes y recibe por semestre alrededor de 5000, son pocos quienes cuentan con las competencias necesarias para iniciar un proceso autónomo de aprendizaje. Tales falencias acarrean múltiples dificultades; por ejemplo, al no tener claras sus motivaciones ante las adversidades, renuncian fácilmente, con lo cual generan altos indices de deserción en las instituciones. Al no ser estudiantes autónomos, sus resultados se transforman en su único estímulo, entonces su preocupación principal es preparar los exámenes y poco se interesan por apropiar un conocimiento, lo cual produce profesionales sin la preparación adecuada para los contextos reales. Al no contar con hábitos de estudio, suelen acumularse de trabajo y convierten el aprendizaje en una angustia; en muchos casos, terminan no adaptándose a la modalidad y desertando.

Por otro lado, el estudiante virtual debe ser un excelente lector y convertirse en uno regular, también debe leer en diversos medios, no solo textos escritos, sino videos, audios, multimedias, objetos virtuales, etc. Con el agravante de que, además, ha de leer muy bien, analizar, apropiar, interpretar, reconstruir y construir nuevos conocimientos a partir de los que ya tiene.

La mejor forma de expresar la adquisición de un aprendizaje es resumirlo o explicarlo con las propias palabras, por eso, es tan relevante que sepa resumir la información de forma escrita, gráfica o diagramática. Entonces, si el estudiante no tiene una disciplina férrea, sucumbirá ante la soledad y terminará abandonando el proceso.

Actualmente, los estudiantes virtuales en su mayoría son emigrantes digitales, por consiguiente, algunos no dominan con solvencia las herramientas tecnológicas para iniciar su proceso de aprendizaje; aquí también hay un mito por vencer: los nativos digitales, al contrario de lo que se cree, tampoco llegan listos en el manejo de las herramientas de aprendizaje; si bien su adaptación es más rápida por su interacción en la red, muchos de ellos nunca han utilizado las TIC en función del aprendizaje (López y Triana, 2013). Por ende, los nuevos estudiantes requieren un entrenamiento tecnológico; no solo operar un programa, sino tener claros los conceptos por aplicar por medio de este. Buscar información en la web es relativamente fácil, pero elegir apropiadamente cuál es relevante y saber qué hacer con ella es algo diferente que nuestros estudiantes poco dominan.

Estudiar de forma virtual no es fácil, tampoco es para todo el mundo, y si a los estudiantes no se les prepara desde el inicio, será más complejo encontrar una excelencia académica. No todos los estudiantes tienen claro que la modalidad exige un compromiso fuerte consigo mismo y una motivación intrínseca y extrínseca. Muchos no han desarrollado hábitos adecuados, tampoco una conciencia de autorregulación o de manejo de tiempo para el desarrollo de sus diferentes actividades. Para Torres (2013), el cambio de mediación implica 
un cambio de estructuras mentales que conlleven una transformación en los hábitos de estudio que en general son mayores exigencias de autorregulación y autodirección.

Muchas instituciones para recibir a sus estudiantes virtuales les proveen de un instructivo o manual de ingreso y manejo de una plataforma. Algunas lo hacen con un texto escrito, otras con un video, otras más con sesiones presenciales. Las anteriores estrategias son válidas, pero insuficientes, pues, en la mayoría de los casos, el estudiante queda obnubilado de tanta información en un periodo tan corto de tiempo, termina asimilando la modalidad sobre la marcha y convirtiéndose en una experiencia poco agradable. Vale entonces el cuestionamiento: ¿qué otras estrategias se pueden implementar para lograr estudiantes exitosos en la virtualidad desde el inicio de su proceso?

En el Politécnico Grancolombiano, donde se desarrolla esta experiencia, se instauraron tres módulos o cursos que preparan a los estudiantes, son transversales a todos los programas y su objetivo es introducirlos en la modalidad. Estos son Técnicas para el aprendizaje autónomo, Herramientas para la productividad y Matemáticas. Aunque dichos módulos o cursos son de gran ayuda para los estudiantes, se ha detectado a través del análisis de los comportamientos de navegación en las aulas virtuales la necesidad de reforzarlos con otras estrategias.

La primera de ellas consiste en un ambiente virtual de aprendizaje (AVA) denominado punto de partida. Su implementación se da por varias razones: los estudiantes inician su exploración en la modalidad y entienden las dinámicas de estudio durante la cursada, es decir, sin el punto de partida no tienen un proceso de inmersión previo. Otra razón es que un solo módulo o curso no es suficiente para mejorar los procesos lectores, manejar adecuadamente la información y tener un pensamiento lógico matemático; estas competencias, por ser transversales, se aplican en diversas ramas del conocimiento.

El propósito principal de este AVA es preparar a los estudiantes para afrontar su vida académica, es decir, entrenarlos para lo que van a vivir en su proceso académico antes de ingresar. Es decir, una inducción no centrada en la institución, sino en lo que será su proceso de aprendizaje.

La segunda estrategia es la caja de herramientas que, como su nombre lo indica, es un conjunto de herramientas organizadas de acuerdo con diferentes necesidades de aprendizaje. Dentro de ellas se encuentra software libre, herramientas en línea de almacenamiento en nube y aplicaciones (apps) para teléfonos inteligentes (smartphones) y dispositivos móviles. El propósito educativo es que el estudiante pueda hacer una gestión más eficiente en su proceso de aprendizaje, pues las herramientas le permiten organizar sus actividades, hacer resúmenes de sus contenidos o teleconferencias, conceptualizar a través del mapeo, 
facilitar la elaboración de proyectos colaborativos, ahorrar y organizar su tiempo, ampliar o profundizar lo visto en el aula virtual.

El estudiante de acuerdo con sus necesidades de aprendizaje ingresa a la caja de herramientas, busca la más apropiada, la descarga y la instala, o se inscribe en ella si tiene un portal que lo permita. Todo con el fin de que pueda utilizarla y sacarle el mejor provecho en su experiencia de aprendizaje; similar a un google store o un android store, portal donde el usuario encuentra las aplicaciones que va a instalar en su móvil; la diferencia es que cada herramienta tiene una finalidad académica determinada y están pensadas para que el estudiante las utilice en diferentes momentos de aprendizaje. La caja de herramientas es transversal a todos sus módulos, le pueden servir en cada uno de ellos o ser específicas para uno determinado.

\section{Antecedentes}

\section{Punto de partida}

Las pruebas de caracterización son unas pruebas iniciales que se realizan para evaluar las competencias transversales (lectoescriturales, matemáticas y tecnológicas) en los estudiantes; el propósito es diagnosticar cómo están para iniciar su proceso. Estas pruebas se vienen realizando en el Politécnico Grancolombiano desde el primer semestre de 2010. De acuerdo con el comportamiento histórico de los resultados, se han podido perfilar algunas dificultades comunes en los estudiantes que ingresan a la modalidad virtual.

En el área de lectoescritura, se detecta una baja comprensión de los textos; se les dificulta a los estudiantes hallar las ideas principales. La siguiente dificultad es la interpretación de un texto a partir de la lectura; les cuesta trabajo hallarle las intenciones o subtextos implícitos; no es fácil para ellos inferir en la lectura. Otra dificultad encontrada es que no logran percibir el texto como una unidad; el estudiante lee el texto, pero no logra relacionar entre sí las distintas proposiciones, lo cual se conoce como lectura fragmentada, por consiguiente, analiza fragmentos sin problemas, pero su interpretación cambia de manera drástica cuando se refiere al texto completo, no es capaz de concebirlo como una unidad. Por último, es muy complejo para el estudiante argumentar a partir de su lectura. Estas tendencias no son exclusivas de los estudiantes del Politécnico Gran colombiano, sino que han sido corroboradas para varios países de América Latina por el reporte de la evaluación internacional Program for International Student Assessment-Organization for Economic and Cooperation Development (PISA-OECD) de 2012, y en Colombia por el Sistema Nacional de Evaluación de la Calidad de la Educación (Icfes, 2013). 
Comunicación, redes, aprendizaje y desarrollo institucional y social

En el área de matemáticas, es común una baja preparación en álgebra y precálculo. A esto se les suma los prejuicios que tienen los estudiantes al respecto, es decir, la creencia generalizada de que las matemáticas son difíciles; muchos estudiantes no presentan la prueba por el temor a fallar en ella (hay que tener en cuenta que es una prueba voluntaria y se hace antes de ingresar a cursar el programa).

También se evidencia un grado de operacionalidad no de análisis, que significa que el estudiante trabaja las matemáticas de manera automática, busca aplicar una fórmula, dar un resultado, en lugar de emplear una lógica matemática y un análisis de lo que se le pregunta, evita pensar el problema antes de intentar resolverlo (Hederich y Camargo, 2000).

En lo tecnológico, se evidencia algo que pareciera poco lógico para una modalidad virtual. Muchos estudiantes tienen poca práctica en el manejo de herramientas de software. Este fenómeno tiene varias causas que se han evidenciado por medio de las entrevistas a los estudiantes: los migrantes digitales no están acostumbrados al manejo de un campus y un aula virtual o LMS (learning management system). En muchos casos, el problema se extiende a los nativos digitales, en ellos es recurrente que inician la navegación sin abrir instructivos o tutoriales confiados en el Politécnico Grancolombiano tras lo cual cometen errores sencillos que afectan su óptimo desempeño. Esta falla tecnológica se debe más a una adaptación al LMS cuando el estudiante inicia su actividad y repercute en un alto número de casos a soporte tecnológico.

También se encuentra una falencia tecnológica más compleja para el buen desempeño académico: la falta de buenos hábitos navegacionales, que significa que los estudiantes no saben buscar adecuadamente la información. Se manifiestan dos tendencias notorias: la primera, una búsqueda muy somera de recursos, se conforman con la primera información que encuentran; la segunda tendencia es que no hacen uso de las bases de datos académicas, ya sea por desconocimiento, ya sea por pereza de navegarlas. Tampoco tienen hábitos de navegacionismo inteligente como el bookmarking, o la citación y referenciación de la información buscada.

El análisis de los resultados de las pruebas, el histórico del comportamiento del ausentismo y la deserción evidenciaron que la apertura de los módulos virtuales mencionados no era suficiente para un adecuado desempeño en la virtualidad. Se requería un entrenamiento previo y una introducción a la modalidad.

En 2009, se crearon dos módulos: Técnicas de aprendizaje autónomo y Herramientas para la productividad. El primero tiene como propósito que el estudiante desarrolle competencias necesarias para desarrollar un proceso autónomo fundamental para trabajar en la 
modalidad, alli se fortalecen procesos como autonomía, manejo de la información, proceso lector, resúmenes y mapeo y proceso escritor. El segundo propende a que el estudiante sea capaz de buscar de manera adecuada información, manejar el aula y el campus virtual, manejar herramientas ofimáticas (Excel, Word, PowerPoint). Las temáticas de los dos módulos son amplias y, aunque ayudan a cómo ser un estudiante virtual exitoso, hacen parte de la malla curricular y el estudiante tiene un proceso de inmersión en la cursada, lo cual acarreó que los aprendices resolvieran sus dudas de manejo de plataforma, de subida de tareas durante la cursada, el propósito académico terminaba en un segundo plano y los tutores terminaban siendo asesores de manejo de plataforma y de soporte tecnológico.

Las encuestas y opiniones de los tutores permitieron pensar una estrategia distinta para apoyar a los estudiantes en 2010. Como respuesta a las solicitudes de los tutores, se crearon manuales de manejo del aula centrados en las dificultades tecnológicas, con temas como ingreso a la plataforma, obtención de usuarios, contraseñas y manejo del aula virtual. Sin embargo, contando con los manuales, persistían las dudas del manejo tecnológico por parte de los estudiantes.

En 2011, se creó un espacio en el campus virtual donde el estudiante podía consultar si tenía instalado el software necesario para el correcto uso del campus y las aulas virtuales. En 2012, se crearon videos tutoriales y videos cápsulas (videos cortos de máximo cinco minutos) con consejos para iniciar en la modalidad (figura 7.1).

Figura 7.1. Servicios tecnológicos para el estudiante campus virtual.

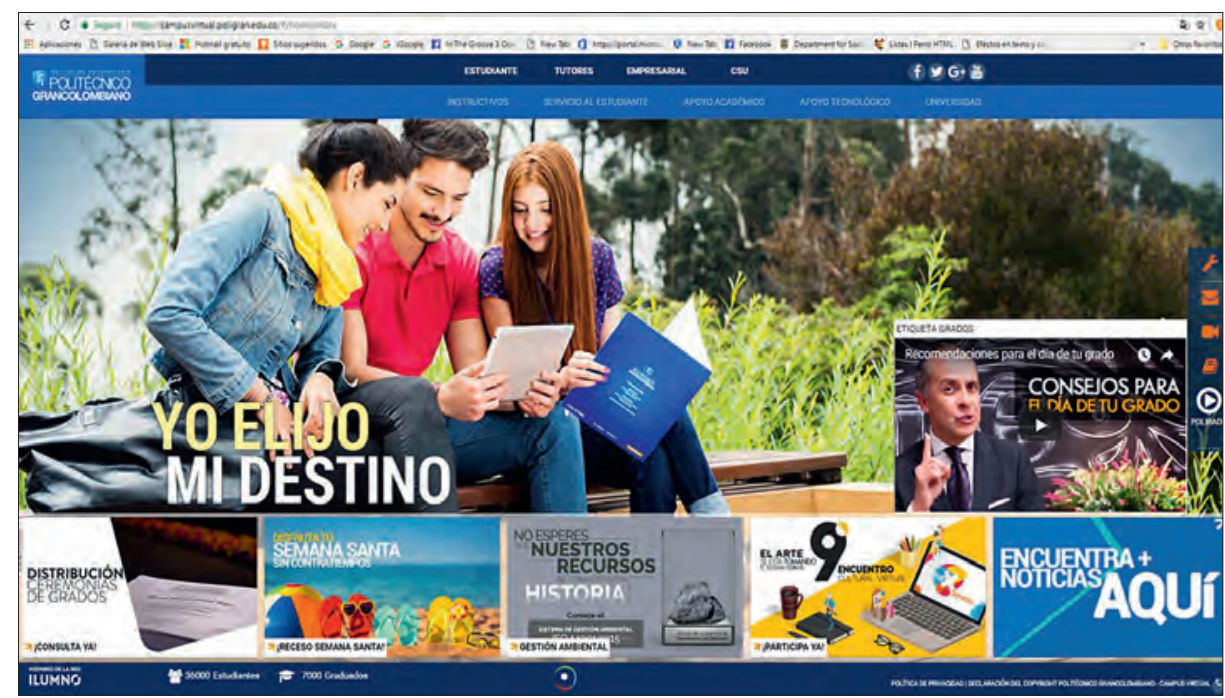

Fuente: Campus virtual Politécnico Grancolombiano (2012). 
Comunicación, redes, aprendizaje y desarrollo institucional y social

En 2013, se creó un espacio denominado mesa de ayuda donde los estudiantes crean sus casos y un equipo de servicio le resuelve el caso en un plazo máximo de 48 horas. Esta práctica todavía se conserva en el campus virtual dentro de las aulas virtuales para que los estudiantes puedan resolver cualquier inconveniente tecnológico que posean (figura 7.2).

Figura 7.2. Mesa de ayuda al estudiante.

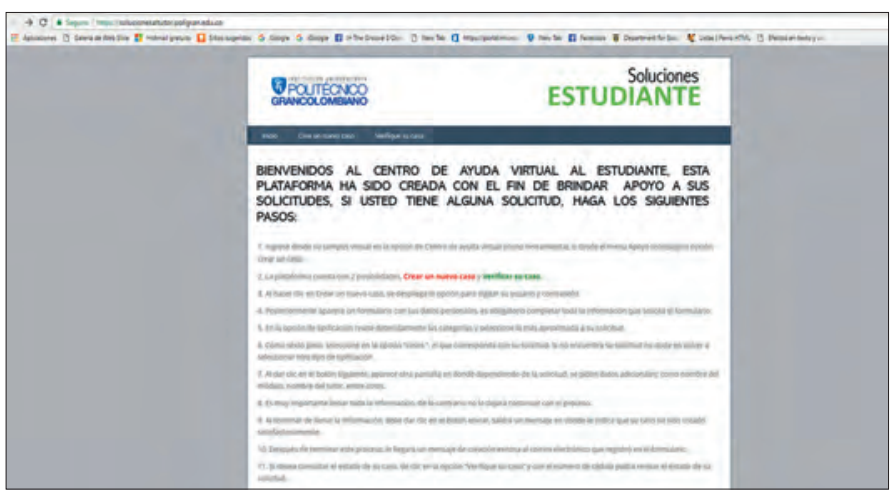

Fuente: Campus virtual Politécnico Grancolombiano (2013).

En el segundo semestre de 2013, se hizo una ruta de bienvenida, que consistía en una serie de materiales escritos, manuales, videos informativos, lo cuales abordaban la parte tecnológica, algunas recomendaciones sobre el proceso lector y algunos ejercicios de matemáticas (figura 7.3). Aunque fue una herramienta funcional y que aprovecharon los estudiantes, la mayoría de los materiales eran objetos informativos que carecían de interacción y se centraban en la consulta.

Figura 7.3. Ruta de bienvenida a los estudiantes.

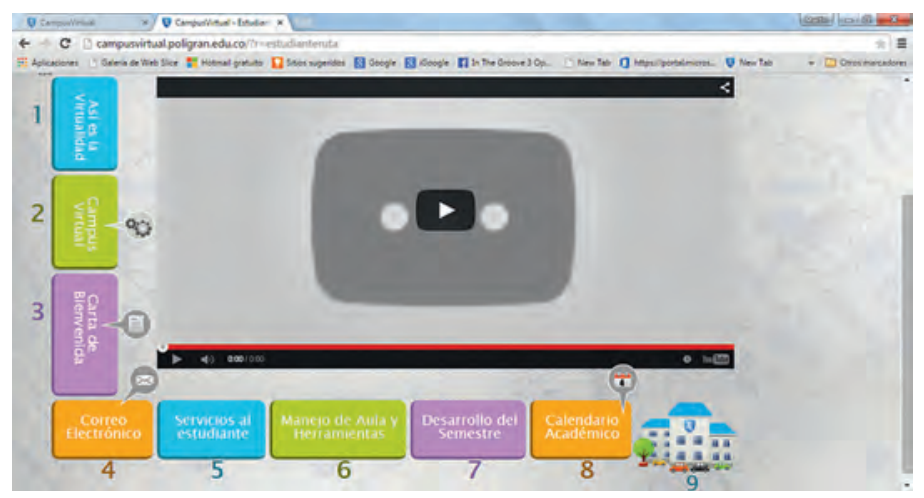

Fuente: Campus virtual Politécnico Grancolombiano (2013). 
Estas prácticas aún se mantienen, porque la pretensión es dejarle al estudiante todos los caminos para facilitarle su proceso. En 2014, con un grupo de académicos trabajó en la creación de un curso introductorio enfocado en que los estudiantes reciban una inmersión en la modalidad. La dificultad fue el tiempo, pues los calendarios institucionales no permitían un periodo previo para realizar el curso antes de iniciar con el semestre propiamente, tampoco se podía agregar un semestre o trimestre de adecuación. La idea era analizar cómo este curso podía contribuir a mejorar la adaptación del estudiante a la modalidad y los resultados académicos. Se pensó en diversas actividades de nivelación, también en sesiones nivelatorias sincrónicas, estrategia que se rechazó por el volumen de estudiantes que ingresa cada semestre. Se optó por hacer refuerzos a los tres cursos ya mencionados.

Al final, se adoptó la estrategia de un curso en línea masivo y abierto (MOOC), porque podía abrirse a todos los estudiantes e interesados en la modalidad, es decir, aspirantes que quisieran conocer la modalidad antes de matricularse. Los estudiantes podían iniciar su exploración en la modalidad y entender sus dinámicas antes de la cursada; servía como un proceso de inmersión previo que ayudaba a mejorar los procesos lectores y matemáticos. Sin embargo, un MOOC, al ser un curso, tenía ciertos formalismos que buscaban obviarse, porque, al ser un producto del gusto de los estudiantes, debía ser menos formal y más un producto de edutainment que fuera motivador e inspirador para el estudiante. Por tal razón, el MOOC inicial se transformó en el punto de partida, se construyó como un AVA donde el estudiante se sumerge y todo su proceso de inducción está embebido en un solo ambiente, presenta videos, audios, objetos de aprendizaje, simuladores, talleres, actividades autoevaluativas. Es decir, tiene características de un MOOC, porque es un curso con estructura, programación y evaluaciones, es masivo (sin límite de participantes) y se desarrolla en línea (Poy y Gonzales-Aguilar, 2014). El punto de partida es una estrategia académica derivada, porque está inmerso en un AVA, significa que es autocontenido, gratuito, de corta duración, aunque es evaluable, no tiene calificación. Sin embargo, no es un MOOC, pero no es abierto, es único para estudiantes del Politécnico Grancolombiano; la estructura, el modelo pedagógico, los simuladores del campus y aula virtual y los servicios son solo para sus estudiantes.

\section{Caja de herramientas}

El proyecto se publica en 2015, pero su gestación se da desde 2013, casi dos años en la búsqueda e indagación de las herramientas apropiadas para las necesidades educativas que se encontraron. No solo es hallar una herramienta, sino que es probarla para ver si cumple el propósito educativo que se espera de ella. 
La idea partió de una experiencia de clase donde se requería que los estudiantes hicieran una sustentación en línea del proyecto final a través de un webinar. De esta actividad, se generó el interrogante: ¿cómo pueden los estudiantes hacer sus diapositivas para la sustentación? Se buscaron dos herramientas para la presentación de trabajos (Prezi, Spicynodes), y la respuesta de los estudiantes fue positiva, porque muchos utilizaron las herramientas en línea para elaborar y luego compartir sus presentaciones, de manera que la actividad ayudó a los estudiantes y a tutores. De esa forma, nacieron las cajas de herramientas como una práctica docente. La primera nació en 2012 para el módulo Herramientas web para la construcción de materiales educativos, donde se compilaron casi ochenta herramientas que le permiten al docente construir materiales con fines didácticos para sus estudiantes agrupadas de la siguiente manera: herramientas para producir videos, editar imágenes, editar audios, hacer textos animados, OVA, juegos de repaso, juegos educativos, infografías, mapas mentales y conceptuales. La segunda caja de herramientas nació en otro curso de Innovación educativa en 2014, donde se realizó una caja pensada para nuevas metodologías mediadas con las TIC. Se dividieron las siguientes categorías: herramientas para hacer wikis, foros, webinar, trabajo colaborativo, bookmarking, edutainment, microlearning, MOOC, realidad aumentada, etc.

La construcción de cajas de herramientas no es una idea original, sino que en la web muchos docentes en sus blogs recomiendan herramientas en línea educativas. Básicamente, las cajas de herramientas son un ambiente personal de aprendizaje (PLE 'personal learning environment'), donde se reúne un grupo de herramientas que le permiten al estudiante lograr un propósito de aprendizaje determinado por el tutor. La innovación radica en crear grupos de herramientas clasificadas, no con propósito de aprendizaje, sino con una necesidad o una labor académica que se quiere que el individuo pueda realizar utilizando herramientas que se encuentran en el ambiente virtual.

La mayoría de las utilidades web no son pensadas para el aprendizaje, sino que es el estudiante o el tutor quien le da una aplicación educativa; por ejemplo, una herramienta para gestionar proyectos empresariales no está pensada para trabajos académicos, pero se puede hacer trabajo colaborativo con ella, entonces se vuelve funcional para la caja de herramientas.

La creación de la caja para las necesidades del estudiante surge en el momento que no se ven las herramientas desde la perspectiva del tutor, sino del estudiante. Se empezaron a recrear situaciones de aprendizaje de acuerdo con lo que los tutores les solicitan a los estudiantes; por ejemplo, las referencias de un trabajo con normas APA; se indagó y se encontraron herramientas en línea que ayudan a la citación solo con introducir los datos de referencia. Así, se prosiguió con la indagación de las herramientas o enlaces de utilidad 
para los estudiantes. De ahí nace el cuestionario central que se busca resolver con la implementación de la caja de herramientas: ¿qué necesita un estudiante para facilitar su gestión académica dentro de su vida estudiantil?

De dicha pregunta nacen las categorías de la caja de herramientas que se tratarán más adelante. Las cajas de herramientas facilitan la labor académica, ya que son muchas las posibilidades o utilidades que puede tener un estudiante, como programar en HTML, aprender un idioma, practicar con ejercicios y explicaciones de matemáticas, física y química. Además, tiene la ventaja que se pueden renovar frecuentemente, de acuerdo con las tendencias educativas, nuevas herramientas que salgan en la web o que el equipo de tutores descubra; es algo dinámico que debe estar en constante actualización. Asimismo, se pueden reemplazar algunas herramientas por otras más novedosas o porque una categoría crece y las utilidades de la aplicación se repiten en dos herramientas diferentes.

Para que la caja de herramientas no se vuelva un cúmulo de herramientas que están sin sentido pedagógico alguno, se debe integrarla a las aulas y las actividades propuestas por el tutor, de esa manera se vuelve significativa para los estudiantes y aumenta su utilización.

\section{Lineamientos teóricos}

\section{MOOC}

Acrónimo de massive open online course (curso en línea masivo y abierto), fueron creados por Stephen Downes en 2008, y están enfocados desde la perspectiva conectivista, la cual se plantea como la teoría para el aprendizaje en línea (Uoctic-grupo6.wikispaces.com, s. f.). Los MOOC son cursos en los que se accede a ellos en línea, en su mayoría son autocontenidos, lo cual significa que las actividades evaluativas son pensadas para ser realizadas de forma autónoma por el estudiante sin la presencia de un tutor, cumpliendo uno de los postulados conectivistas que afirma que el aprendizaje puede residir en elementos no humanos (Siemens, 2004). Algunos cursos tienen tutor de acompañamiento, pero su dinámica educativa está pensada para que no tenga limitaciones en los matriculados (massive). De igual manera, la palabra abierta (open) quiere decir que cualquier persona puede acceder a ellos de forma libre.

\section{Ambiente virtual de aprendizaje}

Es un espacio organizado o configurado con varios recursos didácticos distribuidos en una ruta de conocimientos y conceptos que crean un entorno dinámico con diversas condiciones que facilitan el aprendizaje. La palabra virtual adquiere sentido porque la interacción es 
mediada por la tecnología, la cual transforma la relación educativa, pues facilita la comunicación y el procesamiento de la información con el uso de múltiples medios (multimedia), favoreciendo las diferentes formas de aprender (inteligencias múltiples) y la interacción del sujeto con el objeto, del sujeto consigo mismo y del sujeto con su entorno (ambiente).

Un ambiente está pensado para que el estudiante se sumerja e interactúe con él. Y se compone de los siguientes elementos: un diseño instruccional pensado en los tiempos y las situaciones de aprendizaje de los estudiantes; escenarios donde se desarrollan condiciones favorables desde los contenidos, la motivación y la acción educativa del estudiante; una secuencialidad o niveles de dificultad cognitiva que evidencien la aprehensión por parte del estudiante; y unidades de contenido (multimediales y textuales) y de actividad (evaluativos o autoevaluativos).

El AVA debe tener en cuenta las diferencias individuales y grupales, los intereses y las necesidades del estudiante, esto lo hace atractivo y funcional. Debe contar con diversas interfaces que operan como instrumentos de mediación, además de una estructura comunicativa, porque en su interior debe ocurrir el aprendizaje. Se ha de considerar cómo se va a manejar la comunicación para que las instrucciones y los contenidos sean claros, así como determinar las interacciones con el conocimiento, para lograr la secuencialidad del aprendizaje.

En un AVA, los estudiantes toman decisiones de acuerdo con el entorno a través del uso de diferentes narrativas digitales y actividades de desempeño. Por tal razón, los materiales inmersos en el ambiente se deben seleccionar, elaborar y disponer (accesibilidad y visibilidad) según un modelo pedagógico predispuesto para él. Tal disposición de materiales debe ser acorde con las rutas de aprendizaje. Un AVA como espacio puede disponer de cualquier tipo de materiales que faciliten el proceso de aprendizaje, como textos, imágenes, videos, audios, animaciones, simulaciones, software, hipertextos, hipermedios, glosarios, líneas de tiempos, OVA, etc.

Las responsabilidades del estudiante deben ser bien definidas para que se propicie la autonomía. Un AVA debe propiciar la libertad del estudiante para orientar su acción, ampliar las estrategias de aprendizaje, modificar las estructuras de pensamiento, aplicar estrategias de metacognición para que como aprendiz fusione y transforme sus conocimientos previos con los nuevos para asi mejorar sus habilidades cognitivas.

En otros aspectos, dependiendo de la finalidad educativa y la metodología de aprendizaje, pueden existir objetos de aprendizaje (OA) u objetos virtuales de aprendizaje (OVA) que compongan un AVA, pues el OVA se enfoca más en un aprendizaje puntual, mientras el AVA pretende conformar un universo. Para entender la diferencia, se comparan los dos 
conceptos con un videojuego, donde el usuario (estudiante) entra en una realidad (ambiente) con sus propias reglas. Este jugador o usuario juega según esas reglas (en pedagogía se llaman acuerdos) y va avanzando; según supere diferentes pruebas, retos o mundos (sería el equivalente a la evaluación), pasa a otro nivel. El estudiante culmina el juego y lo gana o lo pierde de acuerdo con las capacidades que ha desarrollado; si es necesario retoma el juego donde quedó hasta superar esa prueba y pasar a otro nivel. En este símil, el AVA sería el juego y el OVA podría ser cada nivel que compone el juego. Es decir, un AVA es el universo que inserta al estudiante en un contexto interactivo a través de una unidad narrativa y multimedial, genera instrucciones o reglas de juego (modelo instruccional) que se van aplicando a medida que el estudiante desarrolla la ruta de aprendizaje mediada por diferentes interfaces (modelo comunicativo), además con múltiples actividades que evidencian las competencias adquiridas hasta convertirlas en vivencias (aprendizaje significativo).

Para que el AVA se convierta en una experiencia de aprendizaje, se requiere que su estructuración sea creíble, para ello, se debe recurrir a las narrativas digitales a fin de cambiar de la percepción de un material meramente informativo a la construcción de un reto educativo. La narración debe insertar los conocimientos, luego propiciar y medir tal aprendizaje; en muchos casos, para facilitar la interacción, es común encontrar avatares o personajes guías del proceso.

El punto de partida como tal es un AVA, aunque tiene algunos elementos del MOOC; por ejemplo, es en línea, el AVA puede ser o no en línea. Está constituido con una ruta pedagógica similar a un curso con cuatro unidades de trabajo cada una con sus competencias definidas. Es de corta duración, está pensado para cursarse en un máximo de dos semanas; sin embargo, los tiempos varían según el ritmo de aprendizaje del estudiante. Se estructuró de forma masiva con actividades autocontenidas, porque está pensado para todas las personas que ingresan a la institución en la modalidad virtual y, aunque los contenidos son de libre acceso, tiene restricciones de acceso, es decir, no cumple con una de las condiciones de un MOOC que sea abierto a cualquier persona.

\section{Personal learning environment}

El entorno personal de aprendizaje (PLE) consiste en una selección de herramientas para que los estudiantes las utilicen y desarrollen con el fin de conseguir un aprendizaje determinado. Nace desde la filosofía de que cada persona es responsable de su proceso, y su propósito es que cada quien encuentre el camino para adquirir nuevas competencias con la ayuda de diversas herramientas planeadas por el tutor para tal fin. También se definen los PLE como sistemas que ayudan a la autonomía de los estudiantes al permitirles a estos tomar el control y gestión de su propio aprendizaje. Según Castañeda y Adell (2013), esto incluye el apoyo a los 
estudiantes para fijar sus propios objetivos de aprendizaje, gestionar su aprendizaje, la gestión de los contenidos y procesos y comunicarse con otros en el proceso de aprendizaje.

EI PLE como un sistema que ayuda al estudiante a tomar el control y la gestión de su aprendizaje marca un cambio fundamental en el papel que los recursos desempeñan, porque es el estudiante quien decide cuáles emplear de acuerdo con sus necesidades e intereses, lo cual aumenta la capacidad para evaluar la información. El aprendizaje, entonces, se enfoca en la indagación, exploración, organización y conjugación de los elementos que requiere para desarrollar aprendizajes. Santamaría (2010) afirma: “En este sentido, la enseñanza es menos una cuestión de transmisión de datos y más un ejercicio colaborativo de recolección, orquestación, remezcla e integración de datos para la construcción del conocimiento".

Un PLE puede estar compuesto por uno o varios subsistemas. Como tal, puede ser una aplicación de escritorio o un conjunto formado por uno o más servicios basados en web (Aula.virtual.ucv.cl, 2012). El PLE reconoce que el aprendizaje es algo permanente y pretende proporcionar herramientas de apoyo para este. También reconoce el papel del individuo a la hora de organizar su propio aprendizaje (Attwell, 2007).

La caja de herramientas funciona similar a un PLE, sin embargo, mientras este tiene una finalidad para un aprendizaje determinado, aquella posee diversas finalidades de acuerdo con las necesidades comunes de los estudiantes. Se puede afirmar que la caja de herramientas integra varios PLE en su interior, porque cada categoría es a su vez un PLE.

La caja de herramientas contiene diversas herramientas web, RSS (Really Simple Syndication), widgets, artefactos y aplicaciones que le ayudan al estudiante en su proceso educativo, gestión académica, acceso y búsqueda de información, diferentes elementos que refuerzan su aprendizaje. Además, las herramientas tienen diversos propósitos, entre ellos, el de conjunción y andamiaje como complementos o aplicaciones de refuerzos pedagógicos, con esto se pueden agrupar documentos, recursos multimedia y software que le permita la gestión del conocimiento de manera significativa. Otro fin es que tengan posibilidades de reorganización, de artefactos de conocimiento y análisis. También se encuentran herramientas de almacenamiento cloud para que pueda acceder de forma fácil a sus resúmenes o apuntes de clase, que le permitan preguntar, desafiar y buscar clarificaciones, formar y defender opiniones, apoyar o enfrentar las opiniones propias con las de los demás. De manejo de la información que le permitan seleccionar y resumir las ideas y el aprendizaje. De presentaciones para elaborar una presentación en diferentes formatos multimedia dependiendo de su necesidad. De representaciones que son herramientas de visualización, tales como software de trazado que hagan posible crear álbumes de recortes, para representar ideas usando pequeños fragmentos multimedia. 
La versatilidad de la caja de herramientas es tal que cualquier tutor puede escoger un tema determinado para crear un PLE e implementarlo; debe procurar que las herramientas no se repitan y que se usen plenamente por los estudiantes de acuerdo con sus estrategias pedagógicas. Sus elementos pueden ser tomados de la web, de libre uso o acceso, o ser creadas y desarrolladas por el tutor ampliando su espectro educativo retando su capacidad didáctica. Es más, se pueden incorporar herramientas propuestas por los estudiantes de acuerdo con sus indagaciones y acorde con lo que ellos requieren para hacer más eficaz su aprendizaje. Además de seleccionar la herramienta, es indispensable explicarle al estudiante cómo manejarla, para ello, se incluyen videos tutoriales en línea.

\section{Lineamientos pedagógicos}

Ya se explicó la fundamentación de la estrategia pedagógica del punto de partida. Ahora se procede a los fundamentos pedagógicos que se tuvieron en cuenta para su elaboración.

- Constructivismo: empleando la teoría piagetinana, el AVA pretende la interacción con el conocimiento, por tal razón le plantea al estudiante la transformación de las estructuras cognitivas conforme a las que ya traía. También se tiene en cuenta la construcción de aprendizajes significativos a medida que la interacción con los contenidos y las actividades motiven a los estudiantes a un cambio que propenda a la construcción de su autonomía.

- Inteligencias múltiples: vista desde múltiples formas de aprender, por eso, los contenidos se presentan en diferentes lenguajes multimedia para que el estudiante aprenda de diversas formas.

- Aprendizaje autónomo: el ambiente no solo depende de la autonomía del estudiante, de sus compromisos y responsabilidades, sino que refuerza el aprendizaje autocontrolado, porque todo funciona a partir de autoevaluaciones y actividades como talleres de práctica y de repaso sin valor en nota, solo enfocadas en el deseo del estudiante por mejorar sus competencias y estar mejor preparado para iniciar su proceso de aprendizaje.

- Conectivismo: de esta teoría, se toma el postulado de que el aprendizaje radica en factores no humanos, pues la interacción del estudiante será con su ambiente de aprendizaje.

- Aprender haciendo: una parte del AVA corresponde al manejo del aula virtual, allí, en lugar de un tutorial donde el estudiante se limita a consultarlo, se hizo un simulador donde el estudiante debe hacer el recorrido paso a paso, de esa manera, aprende el manejo de la herramienta a partir de sus acciones.

- Aprendizaje ubicuo: como el punto de partida se puede consultar desde cualquier 
conexión a la red, incluso desde dispositivos móviles, cumple con los requerimientos de fácil acceso y fácil navegabilidad.

Por su parte, algunos lineamientos pedagógicos de la caja de herramientas coinciden con los del punto de partida, como el aprendizaje autónomo, el aprender haciendo, el aprendizaje ubicuo, pero ella se encuentra más inmersa en el conectivismo, donde las conexiones son primordiales para la gestación del aprendizaje. Igual tiene bases en el constructivismo, porque emplea el aprendizaje por descubrimiento o heurístico, ya que promueve que el aprendiz adquiera los conocimientos por sí mismo, de tal modo que el contenido que se va a aprender no se presenta en su forma final, sino que debe ser descubierto (Melero, 2000).

Se toma la curiosidad y las necesidades del estudiante para que, por medio de sus observaciones, comparaciones y análisis, tome sus decisiones y realice sus descubrimientos de manera activa. Toma algunos aspectos de lo que Bruner (1980) denomina el andamiaje consistente en brindar guía y apoyo a los estudiantes para que puedan desarrollar diferentes destrezas, conocimientos y actitudes. Pues el estudiante puede formular suposiciones intuitivas que posteriormente confirma con el uso de las herramientas seleccionadas potenciando la metacognición y la aprehensión.

\section{Metodología}

\section{Punto de partida}

El punto de partida se estructuró a partir de cuatro unidades importantes para iniciar en la virtualidad. Cabe resaltar que no es un curso de inducción, que no se centra en la presentación de la institución, sino que es un ambiente donde el estudiante hace una inmersión y se prepara para la virtualidad, con recomendaciones y métodos que le ayudarán a ser un estudiante exitoso. Lo provee de información con respecto a sus competencias básicas brindándole actividades nivelatorias, el manejo de citas y referenciación. Pero no se queda solo en la concepción académica, sino que también trabaja la parte humana necesaria en un proceso virtual, como la motivación, la autonomía, los hábitos de estudio y la búsqueda de la información.

La estructura del punto de partida es la siguiente:

- Unidad 1. ¿Qué significa ser un estudiante virtual?: esta unidad se centra en el compromiso que adquiere el estudiante consigo mismo al ingresar a la virtualidad, se hace por medio de un texto reflexivo y una serie de videos donde se propone que la 
palabra virtual viene de virtuoso, esto para que sea claro que la virtualidad requiere una fuerte exigencia y compromiso.

- Unidad 2. Conoce tu campus y tu aula virtual: consiste en un simulador que explica el paso a paso de la navegación y le permite simular todo el recorrido por el campus, las aulas virtuales y el correo institucional. Aprende el manejo de las herramientas tecnológicas por medio del hacer.

- Unidad 3. Cómo ser un estudiante virtual exitoso: aquí se tiene una serie de actividades, textos, talleres, videos y OVA para que el estudiante cambie sus hábitos de estudio, gestione su tiempo, adquiera un método apropiado de lectura (textos, videos, imágenes) y un método para la búsqueda y resumen de la información.

- Unidad 4. ¿Estás preparado para la virtualidad?: aquí son dos cursos breves con pruebas de autoevaluación en lectura y matemáticas para que el estudiante haga un diagnóstico de cómo llega a iniciar su proceso de aprendizaje virtual. Los dos minicursos tienen talleres, ejercicios de práctica, autoevaluaciones y videos de retroalimentación para que pueda identificar falencias o vacíos en sus conocimientos previos que serán necesarios en su trabajo académico.

\section{Proceso de implementación del punto de partida}

En primer lugar, se reunió un grupo interdisciplinario de tutores para diseñar el punto de partida en las áreas de matemáticas y lectura. Se definieron las estrategias pedagógicas para estos dos minicursos. Simultáneamente se diseñaron las otras unidades. Con el equipo de pedagogos de educación virtual, se trabajó el proceso de autonomía y hábitos de estudio. Con el equipo de ingenieros, se elaboraron los simuladores de las aulas virtuales. Se diseñaron los contenidos: textos escritos, videos y objetos virtuales. Se elaboraron las actividades evaluativas. Se redactaron los textos que están dentro del AVA. Se editaron Ios videos y audios. En algunas partes, se elaboraron OVA con textos animados, donde el estudiante, de acuerdo con botones e interacciones, elige su ruta de visualización y consulta de recorridos.

Al material se le aplicó diseño gráfico con interfaces que se componían de avatares fotográficos, con el fin de obtener una mayor proximidad de los estudiantes, tales avatares brindan información y los guían en el recorrido del AVA. Para terminarlo, se integró todo en una sola interfaz por medio del programa Storyline. Luego, se montó en un servidor para la consulta.

Se hizo la prueba con un grupo piloto de navegación. Al final, se publicó a los estudiantes en el siguiente enlace http://campusvirtual22.poligran.edu.co/informacion/principal/story.HTML 
Comunicación, redes, aprendizaje y desarrollo institucional y social

Figura 7.4. Portada punto de partida.

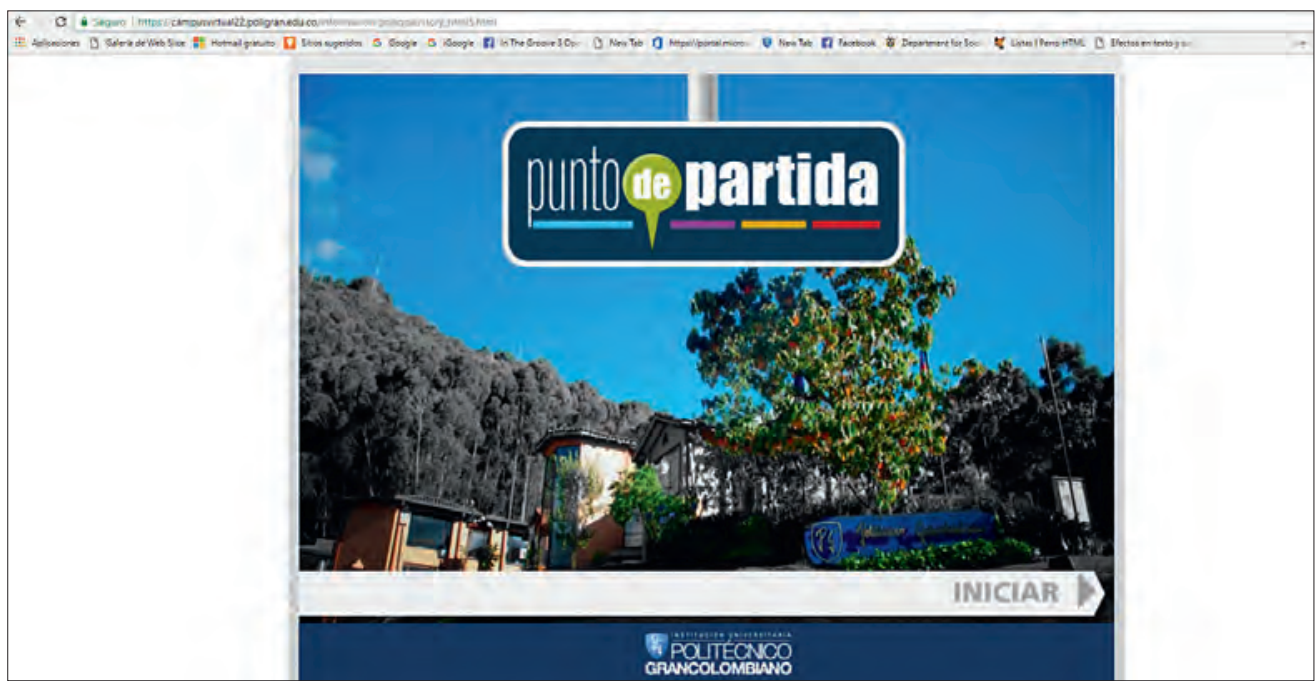

Fuente: http://campusvirtual22.poligran.edu.co/informacion/principal/story.html

\section{Caja de herramientas}

Como ya se describió, la caja de herramientas nació como una práctica en el aula de clases que se empezó a visualizar desde las necesidades del estudiante. Se implementó con la estructura de página web organizada de acuerdo con los requerimientos académicos del estudiante, se accede por un menú principal que redirecciona a diferentes páginas, cada una de ellas con herramientas web o de software que tienen una finalidad de aprendizaje específica. Dependiendo del recurso, se puede descargar e instalar o simplemente el usuario se registra y trabaja en línea, ya que gran parte de ellas son tipo cloud.

Para su implementación, lo primero que se hizo fue construir las categorías y subcategorías, que son un aspecto fundamental porque permiten agrupar las herramientas, orientar al estudiante y encontrar rápidamente lo que este requiere. La clasificación se hizo según las necesidades que se consideraron prioritarias para los estudiantes. El objetivo es que la dirección académica de cada programa indique las herramientas que les pueden servir a aquellos y así incorporarlas a la caja de herramientas.

Las categorías se relacionan con las competencias transversales de la institución que son comunes en los distintos programas curriculares, por ejemplo las competencias comunicativas (lectura, escritura, habla y escucha), entre otras. También se dejó una categoría 
para las herramientas que se emplean en áreas específicas del conocimiento, como programación, física, química, matemáticas, finanzas, etc.

En la parte izquierda de la figura 7.5, se puede ver el menú que corresponde con las diferentes categorías de la caja de herramientas.

Figura 7.5. Menú principal caja de herramientas.

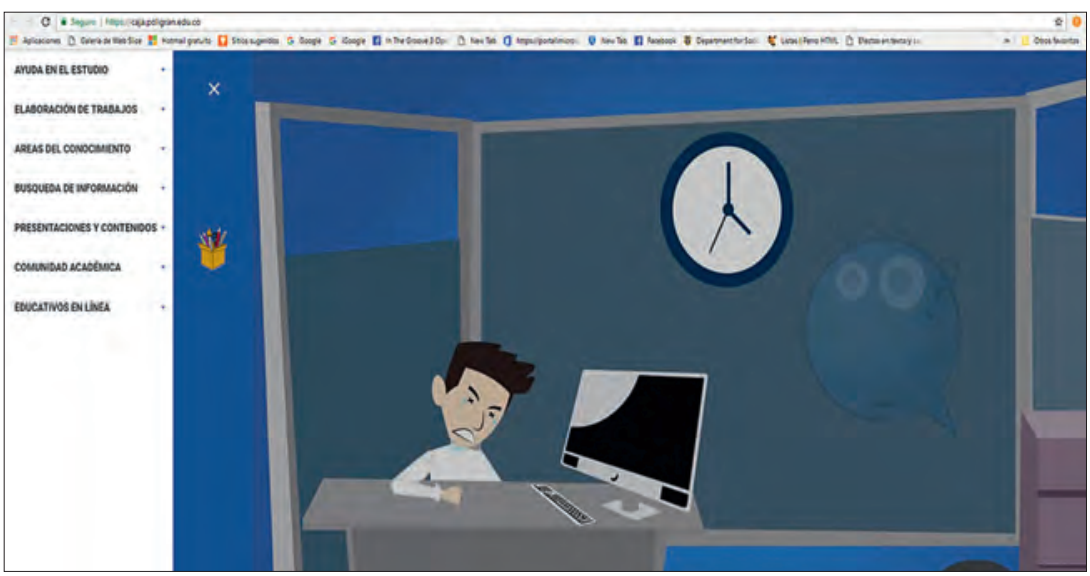

Fuente: http://caja.poligran.edu.co/

Las categorías son las siguientes:

- Herramientas de ayuda en el estudio: están pensadas para mejorar la forma de estudiar y modificar algunos hábitos de estudio. La idea es que le faciliten al estudiante su vida académica y su gestión educativa, se emplean para actividades como hacer apuntes de clase, mapas conceptuales o mentales, resúmenes, organizar las actividades y el calendario académico, así como para mejorar las competencias de análisis de lectura, lectura de indagación y lectura eficiente.

- Herramientas para la lectura: ejercicios y consejos para mejorar el nivel de lectura, ejercicios para la lectura comprensiva y la lectura rápida.

- Herramientas para resumir la información: se dividen en herramientas para elaborar mapas conceptuales, mapas mentales y diagramas.

- Herramientas para resúmenes visuales: se dividen en herramientas para elaborar nubes de palabras o tableros de anotaciones.

- Flash cards o tarjetas de apuntes: se emplean para tomar apuntes de las clases, ideales cuando se ven videos o escuchan audios e ir realizando apuntes. Algunas son de utilidad para crear ficheros de resumen o notas de clase, asi como bitácoras. 
Comunicación, redes, aprendizaje y desarrollo institucional y social

- Organizador de tareas: son herramientas para gestionar tiempo y manejar una agenda de tareas y actividades con recordatorios que permite la organización del estudio.

- Tipeo: son herramientas de entrenamiento para escribir rápido en el teclado del computador.

- Herramientas metodológicas: se emplean para organizar y dar respuesta a las estructuras de desarrollo de trabajos y estructurar un pensamiento académico. Son especiales para presentar trabajos o proyectos de investigación. También hay herramientas para el citado, para la correcta redacción, diccionarios para el PC (Diccionario de la Real Academia Española) o el smartphone. Si el trabajo es en grupo, hay herramientas para gestionar proyectos que permiten trabajar mancomunadamente y luego enviar la versión final al tutor.

- Herramientas para la redacción de textos: herramientas y ejercicios para mejorar la ortografía y la redacción.

- Diccionario: de términos en español, para el uso en dispositivos móviles y de traducción de palabras en otros idiomas.

- Cómo elaborar artículos de investigación: pautas y consejos para elaborar un artículo de investigación.

- Cómo elaborar ensayos: guía para elaborar ensayos.

- Cómo elaborar un proyecto de investigación: presenta varias herramientas para gestionar documentos de investigación, de referencias bibliográficas, para el citado de archivos y para realizar trabajo investigativo de manera colaborativa. También se encuentra un listado de organizaciones que se encargan de financiar proyectos de investigación.

- Cómo referenciar y cómo citar: se encuentran gestores de citas y referencias de libros en normas APA, MLA, Chicago, Vancouver y Harvard.

- Herramientas de búsqueda y almacenamiento de información: facilitan las búsquedas de carácter académico, útiles en diferentes ámbitos para investigaciones, consultas, intereses, bases de datos de la institución y abiertas, acceso a hemerotecas y bibliotecas. También herramientas para hacer bookmarking que significa seleccionar las páginas favoritas en internet donde hay información relevante o de referencia.

- Consulta de información: son herramientas que nos facilitan las búsquedas de carácter académico o son bases de datos institucionales que ayudan a encontrar información de tipo académico.

- Bibliotecas y metabuscadores: incluye todas las bases de datos a las que está adscrita la institución, repositorio, hemeroteca y catálogo institucional.

- Marcadores sociales (bookmarking): es un espacio donde el usuario puede reseñar y guardar aquellos enlaces a sitios webs de interés académico o investigativo.

- Almacenamiento y transferencia de archivos: es pensado para un volumen grande de información que se puede dejar o compartir en la nube. 
- Herramientas para hacer presentaciones, páginas web, blogs o wikis: útiles para cuando el estudiante hace una presentación o sustentación, no solo en sus módulos, sino en lo profesional o personal. La presentación puede ser con diapositivas, líneas de tiempo, infografías, mapas mentales, textos animados, página web, un blog o una wiki.

- Herramientas para hacer presentaciones: presentaciones en diferentes formas y formatos.

- Wikis: se trata de herramientas para el trabajo colaborativo, cuyas páginas pueden ser editadas por varios usuarios.

- Blogs: Para hacer diarios de trabajo académico o apuntes.

- Páginas web: son plantillas para crear diferentes páginas de manera rápida.

- Herramientas de comunicación y de comunidad académica: especiales para comunicarse con los compañeros y trabajar de manera colaborativa, permiten crear encuentros sincrónicos, chat, videoconferencias o webinar y compartir archivos. Recomendadas para organizar trabajos y realizar sesiones en grupo para un proyecto determinado. También se pueden crear redes sociales educativas o generar comunidades de aprendizaje y de práctica.

- Planificación y gestión de proyectos colaborativos: estas herramientas ofrecen la posibilidad de crear un proyecto y administrarlo de forma colaborativa, permiten gestionar hitos y tareas, controlar el calendario, disponer de mensajería instantánea y gestionar archivos.

- Gestión colaborativa de documentos: se emplea para crear documentos de texto, hojas de cálculo y presentaciones en línea, así como para trabajar un documento en la nube desde cualquier lugar y con diferentes personas.

- Herramientas de comunicación: útiles para el intercambio sincrónico con chat, videoconferencias, se pueden compartir archivos.

- Redes sociales: se emplean para crear redes sociales con finalidad académica.

- Redes laborales: son redes de conexión profesional donde se puede tener oferta e intercambio con colegas u ofrecer la hoja de vida para situaciones laborales. A su vez, se integran redes de investigadores para quienes quieran hacer intercambios.

- Comunidades de aprendizaje y de práctica: pensadas para trabajar de forma colaborativa, crear, modificar y editar documentos, utilizar un sistema de mensajes internos tipo tabla de boletines, administrar y compartir documentos, registrar juntas y discusiones, publicar contenidos, compartir recursos y alimentación RSS, hacer blogging, construir y administrar grupos, crear relaciones entre grupos y usuarios, crear metarredes. Existe un espacio para el financiamiento de proyectos de investigación y emprendimiento.

- Herramientas de ayuda en la carrera: para los módulos propios de los diferentes programas curriculares, y son específicas centradas en la temática de un módulo. Este 
espacio está en constante actualización de acuerdo con las nuevas herramientas y las indicaciones de los departamentos académicos.

- Matemáticas y estadística: calculadoras, graficadoras, editores de ecuaciones y ejercicios en matemáticas, álgebra, estadística, cálculo y trigonometría.

- Física y química: tablas periódicas, graficadores de compuestos orgánicos, calculadoras de peso molecular, balanceos, convertidores de energía. Herramientas para la física, como convertidores de unidades, laboratorios y clases.

- Sistemas y electrónica: especializadas para aprender a programar en HTML y Java y simuladores electrónicos como protoboards y circuitos eléctricos.

- Idiomas: para reforzar el aprendizaje de las lenguas.

- Educación: para la didáctica y la educación en la primera infancia.

- Geografía e historia: mapas geográficos, estadísticos e históricos. El atlas mundial permite ver la situación de los continentes, mares, océanos y otras formaciones geográficas. Mapas de la historia y de páginas con narrativa de la historia del mundo.

- Finanzas y economía: calculadoras, simuladores, convertidores, test, gestión de las finanzas personales.

- Contabilidad: clases virtuales de contabilidad.

La figura 7.6 muestra las diferentes áreas del conocimiento que involucra la caja de herramientas, que pueden aumentarse según lo que se requiera desde la parte académica para sus programas. Esta es dinámica y se modifica regularmente.

Figura 7.6. Categoría de herramientas de ayuda en la carrera.

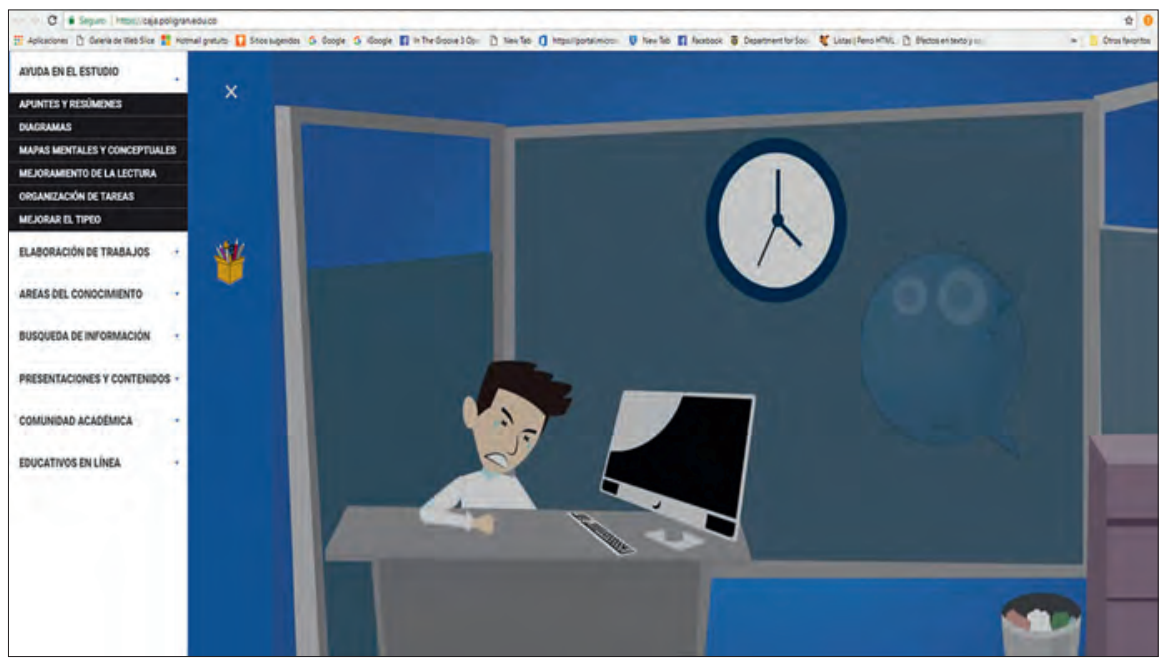

Fuente: http://caja.poligran.edu.co/ 
- Recursos educativos en línea: accesos a recursos gratuitos de diferentes organizaciones y universidades en el mundo. Hay canales educativos de algunas de las universidades más prestigiosas del mundo donde profesores de alto reconocimiento le permiten al estudiante complementar, profundizar o entender los temas vistos en el aula.

- Recursos educativos generales: son recursos educativos para las diferentes áreas del conocimiento. También se incluyen portales con cursos en diferentes temas para que el estudiante pueda inscribirse y cursarlos.

- Canales de videos educativos: son videos de índole educativa, son abiertos y de instituciones de gran reconocimiento, como el canal de Stanford en YouTube que contiene conferencias de profesores, eventos, noticias e información de todas las asignaturas.

- Biblioteca virtual: se habilitará un espacio denominado Biblioteca Virtual, donde estarán los libros de texto de cada uno de los módulos para que el estudiante los pueda consultar. Cuando un estudiante esté en semestres avanzados y necesite consultar el libro texto de un módulo que ya ha visto, puede hacer esa consulta. Por otro lado, también se van a incluir las publicaciones digitales editadas por el Politécnico Gran colombiano.

En el transcurso de la indagación, se encontró que las herramientas también son útiles para los tutores; por consiguiente, se hizo una catalogación adicional: se implementó una caja de doble utilidad para producir contenidos con fines académicos, asî:

Herramientas para producir audios y videos: permiten grabar y editar audios y videos en el computador. La finalidad es que sean videos educativos y puedan reforzar o dar respuesta a las inquietudes de los estudiantes durante la tutoría. Asimismo, se pueden producir podcast que ayuden a los estudiantes con los diferentes temas:

- Grabación de videos: se emplea para grabar videos de distintas fuentes, como dispositivos externos, la pantalla del ordenador, convertir el video en streaming y webcam.

- Grabación de podcast: permite grabar un audio desde cualquier aplicación y publicarlo. El podcast es un audio que se encuentra en la web con contenido académico.

- Edición de videos: se emplea para editar videos en línea y cuenta con la posibilidad de editarlos en alta definición, añadir textos, imágenes, sonidos, efectos especiales, música e incluso transiciones en 3D.

- Edición de audio: sirve para grabar audio en directo, editarlo y exportarlo para publicarlo.

Herramientas para elaborar materiales virtuales: especiales para la producción de materiales con fines educativos, publicar libros, crear juegos, hacer multimedias, infografías, 
encuestas y evaluaciones. El tutor puede publicar diversos materiales o actividades para innovar en el aula:

- Editores de imagen: editar fotos e imágenes.

- Elaborar videodiapositivas: permite agregarle a una presentación o diapositiva el audio para hacerle la narración.

- Herramientas para hacer fotorrelatos: permite hacer una serie de imágenes narradas por voz en off.

- Tablero digital: es un tablero donde se evidencia en la pantalla lo que escribe el tutor como una pizarra de clase, se graba lo que se escribe y permite agregar imágenes y grabar la voz para hacer una lección interactiva.

- Elaborar infografías: La infografía es un diseño gráfico en el que se combinan textos y elementos visuales con el fin de comunicar información precisa sobre variadas temáticas.

- Gráfico interactivo: se toma una imagen y se le crean múltiples puntos activos o vínculos en partes específicas y se convierte en un objeto multimedia.

- Libros multimedia: son herramientas para crear libros digitales y puede ser muy útil para la construcción de documentos de texto, permiten insertarle contenidos multimedia y convertirse en un libro interactivo.

- Herramientas para hacer cómics: con fines educativos ideales en contextos infantiles o juveniles, funciona muy bien con los adultos.

- Herramientas para hacer avatar y animaciones: estas herramientas permiten crear videos de animación en 3D o en 2D que convierten las palabras en una película de animación. Algunas tienen la ventaja de que se puede hacer interacción sincrónica entre los estudiantes y los tutores por medio de la herramienta.

- Herramientas para hacer actividades evaluativas y encuestas: se emplean para hacer actividades como cuestionarios, pruebas, encuestas y test.

- Herramientas para hacer juegos: son actividades de repaso en forma de juegos y videojuegos. Tienen la ventaja que el tutor no debe ser un experto en programación para poder realizarlas.

- Herramientas web para hacer materiales multimedia completos: no solo se emplean para hacer OVA, sino todo un conjunto de objetos que podemos empaquetar en un AVA.

- Listas de software educativos: son listados de software gratuitos que el tutor puede descargar con diferentes fines académicos.

Estas categorías agrupan las herramientas, pero cada una por sí sola no tiene sentido, sino que cada una debe contar con una descripción que explica qué es la herramienta y para qué sirve. Esta orientación es primordial para que el estudiante no divague con las que no 
cumplan sus necesidades y la caja se vuelva un elemento decorativo para su aprendizaje. Una falla común de los portales de aplicaciones es que están allí, pero, en definitiva, el usuario no sabe para qué se emplean y por eso no las indaga.

Después de la descripción está el vínculo de descarga o de ingreso que nos lleva a la herramienta propiamente dicha. Hay herramientas para descargar e instalar, otras son cloud, en ellas el estudiante debe inscribirse con un correo o un usuario y una contraseña, después puede ingresar desde cualquier computador, además todo lo que desarrolle queda disponible en un enlace de publicación. Otras son aplicaciones que se descargan al celular, la tableta o el PC de acuerdo con su sistema operativo.

Por último, después de la explicación y el enlace de acceso hay un video tutorial que explica cómo manejar la herramienta, pues se hace necesario que existan instrucciones de cómo hacerlo, aunque muchas son inductivas; no todos los estudiantes tienen las mismas competencias en el manejo tecnológico. El tutorial facilita el manejo de la herramienta y brinda consejos o secretos para sacarle mejor provecho.

Definidas las categorías se empezó la indagación sobre las herramientas en la web. Esta indagación duró casi dos años, pues existen muchas herramientas, con excelentes y variadas características. Sin embargo, muchas se descartaron porque eran limitadas en sus funciones, otras porque tienen una versión de prueba de treinta días y luego se cierran y, por ende, no se emplean para la continuidad en el proceso del estudiante. Otras herramientas muy interesantes son pagas, un lineamiento es que las incluidas en la caja deben ser gratuitas o de libre acceso, de lo contrario pierden sentido como PLE.

Ante estas dificultades, se definieron varios criterios de selección:

- Herramientas de fácil accesibilidad en la web o de fácil instalación.

- Herramientas de fácil manejo para el estudiante.

- Herramientas que no requieran descarga de programas adicionales para funcionar.

- Herramientas que permitan la publicación de lo que hace el estudiante.

- Herramientas que le permitan al estudiante hacer lo que esta propone.

- Herramientas que sirvan en diferentes tipos de dispositivo (PC, tabletas smartphones).

- Herramientas y materiales gratuitos o de uso abierto, disponibles en la web, solo se hacen los enlaces desde la caja.

- A continuación, en la tabla 7.1, se presenta el listado de las herramientas seleccionadas para la caja. 
Tabla 7.1. Herramientas que se incluyen en la caja

\begin{tabular}{|c|c|c|}
\hline Categoría & Subcategoría & Herramientas \\
\hline \multirow{9}{*}{ 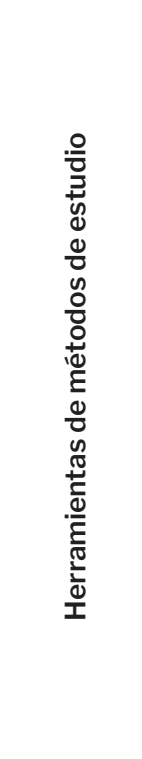 } & Herramientas para la lectura & $\begin{array}{ll}\text { - } & \text { Ejercicios para la lectura rápida } \\
\text { - } \quad \text { Tejercicios de lectura } \\
\text { - } \quad \text { Ejercicas de estudios de comprensión lectora lectura veloz }\end{array}$ \\
\hline & Mapas conceptuales & $\begin{array}{l}\text { - } \quad \text { CmapTools: descarga en PC } \\
\text { - } \quad \text { Bubbl.us: mapas en línea }\end{array}$ \\
\hline & Mapas mentales & $\begin{array}{l}\text { - Mindomo: mapas hipervínculados y notas } \\
\text { - Mindmeister: exporta en PDF, RTF y JPG }\end{array}$ \\
\hline & Diagramas & $\begin{array}{l}\text { - Giffly: diagramas y organigramas } \\
\text { - } \quad \text { Flowchart: diagramas de flujo }\end{array}$ \\
\hline & Nube de palabras & $\begin{array}{ll}\text { - } & \text { Tagxedo } \\
\text { - } \quad \text { Tagul } \\
\end{array}$ \\
\hline & Tablero de anotaciones & - Glogster \\
\hline & Flash cards & $\begin{array}{ll}\text { - } & \text { ExamTime: memofichas } \\
\text { - } \quad \text { Quizlet: crea ficheros y juegos de contenidos } \\
\text { - } \quad \text { Studyepad: bitácoras de aprendizaje } \\
\end{array}$ \\
\hline & Organizadores de tareas & $\begin{array}{l}\text { - } \quad \text { Remember The Milk: organizador de tareas } \\
\text { - } \quad \text { Evernote: organizador de notas y tareas } \\
\quad \text { Anydo: administrador de tareas }\end{array}$ \\
\hline & Tipeo & - Type Fu: escribir rápido en el teclado \\
\hline \multirow{6}{*}{ 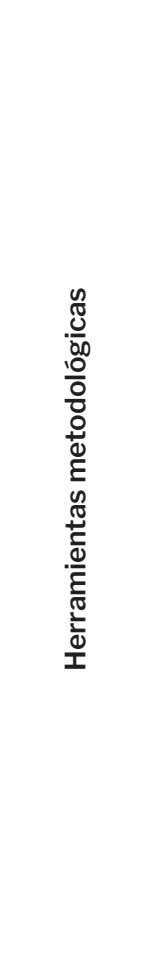 } & $\begin{array}{l}\text { Herramientas para la redacción } \\
\text { de textos }\end{array}$ & $\begin{array}{ll}\text { - } & \text { Ejercicios de ortografía } \\
\text { - } & \text { Ejercicios de redacción } \\
\text { - } & \text { Test de ortogros de redacción } \\
\text { - } & \text { Gramática y ortografía } \\
\text { - } \quad \text { Corrección de estilo } \\
\text { - } \quad \text { Tibro la cocina de la escritura } \\
\text { - } \quad \text { Storybird: para escribir cuentos historietas } \\
\text { - } \quad \text { celtx: para escribir guiones }\end{array}$ \\
\hline & Herramientas de diccionario & $\begin{array}{ll}\text { - } & \text { Diccionario de la Real Academia Española } \\
\text { - } \quad \text { Diccionario para dispositivos móviles } \\
\quad \text { Wordreference }\end{array}$ \\
\hline & $\begin{array}{l}\text { Cómo elaborar un artículo cien- } \\
\text { tífico }\end{array}$ & $\begin{array}{l}\text { - } \quad \text { Cómo escribir un artículo científico } \\
\text { - } \quad \text { Cómo escribir un artículo de investigación (video) } \\
\text { - }\end{array}$ \\
\hline & Cómo elaborar un ensayo & $\begin{array}{l}\text { - } \quad \text { Pautas para elaborar un ensayo } \\
\text { - } \quad \text { Guía básica básica para elaborar un ensayo } \\
\text { - } \quad \text { Herramientas para escribir un ensayo } \\
\end{array}$ \\
\hline & $\begin{array}{l}\text { Cómo elaborar un proyecto de } \\
\text { investigación }\end{array}$ & $\begin{array}{ll}\text { - } & \text { Google Drive: herramienta de investigación } \\
\text { - } & \text { Zotero: gestiona documentos de investigación } \\
\text { - } & \text { Mendeley: gestiona referencias bibliográficas } \\
\text { - } \quad \text { Financiaciónizar artículos de investigación } \\
\text { - } \quad \text { Colciencias } \\
\text { - Unnu: facilita el trabajo en grupo }\end{array}$ \\
\hline & Gestor de citas & $\begin{array}{l}\text { - } \quad \text { KnightCite: APA, MLA, Chicago } \\
\text { - } \quad \text { Chitesforme: Vancouver y Harvard }\end{array}$ \\
\hline
\end{tabular}




\begin{tabular}{|c|c|c|}
\hline Categoría & Subcategoría & Herramientas \\
\hline \multirow{5}{*}{ 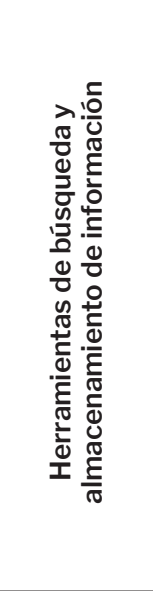 } & Consulta de información & $\begin{array}{l}\text { - } \quad \text { Google Book } \\
\text { - } \quad \text { instabd: descargar y compartir documentos } \\
\quad \quad \text { motor de búsqueda semántico }\end{array}$ \\
\hline & $\begin{array}{l}\text { Biblioteca y metabuscadores del } \\
\text { Politécnico Grancolombiano }\end{array}$ & $\begin{array}{ll}\text { - } & \text { Bases de datos } \\
\text { - } & \text { Recursos digitales por facultad } \\
\text { - } & \text { Hemositorio de documentos } \\
\text { - } \quad \text { Redes nacionales e internacionales } \\
\quad \text { Catalogo en línea }\end{array}$ \\
\hline & Bookmarking & $\begin{array}{ll}\text { - } & \text { Netvibes: escritorio de direcciones } \\
\text { - } \quad \text { Pearltrees: collares de URL } \\
\text { - Diigo: gestión personal del conocimiento }\end{array}$ \\
\hline & $\begin{array}{l}\text { Almacenamiento } \\
\text { y transferencia en línea }\end{array}$ & $\begin{array}{l}\text { - } \quad \text { Dropbox: almacenamiento en nube } \\
\text { - } \quad \text { Google Drive } \\
\text { WeTransfer: transferencia de archivos grandes }\end{array}$ \\
\hline & Aplicaciones educativas & - EduApps \\
\hline \multirow{4}{*}{ 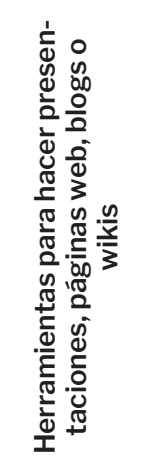 } & Elaborar presentaciones & $\begin{array}{ll}\text { - } & \text { Prezi } \\
\text { - } & \text { Spicynodes: mapas mentales interactivos } \\
\text { - } & \text { Slidesheas de tiempo: cronologías } \\
\text { - } & \text { SlideRocket: diapositivas } \\
\text { - } \quad \text { PowToon: presentaciones con audio } \\
\quad \text { Emaze }\end{array}$ \\
\hline & Wiki & $\begin{array}{l}\text { - Wikidot } \\
\text { - } \text { wikispaces }\end{array}$ \\
\hline & Blogs & $\begin{array}{ll}\text { - } & \text { Blogger } \\
\text { - } & \text { Edublogs }\end{array}$ \\
\hline & Páginas web & $\begin{array}{l}\text { - Webnode } \\
\text { - Wix } \\
\end{array}$ \\
\hline \multirow{6}{*}{ 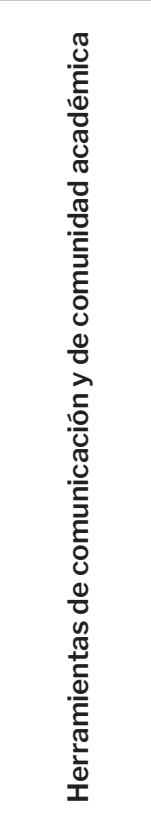 } & $\begin{array}{l}\text { Gestión de proyectos } \\
\text { colaborativos }\end{array}$ & $\begin{array}{ll}\text { - } & \text { Zoho Projects } \\
\text { - } \quad \text { Coambox } \\
\text { - } \quad \text { Conceptive: gestión de proyectos en línea } \\
\quad \quad \text { las comparte conade el equipo } \\
\text { - } \quad \text { Corkboard: tablón colaborativo para poner pósit }\end{array}$ \\
\hline & $\begin{array}{l}\text { Gestión colaborativa } \\
\text { de documentos }\end{array}$ & $\begin{array}{l}\text { - } \quad \text { Google Docs: suite ofimática de Google } \\
\text { - Zoho Docs: suite ofimática en línea }\end{array}$ \\
\hline & Encuentros sincrónicos o webinar & $\begin{array}{ll}\text { - } & \text { Google + } \\
\text { - } & \text { Skype } \\
\text { - } & \text { Joinebinar } \\
\text { - } & \text { ShowDocompartir el contenido de pantalla } \\
\end{array}$ \\
\hline & Redes sociales & $\begin{array}{ll}\text { - } & \text { Facebook } \\
\text { - } & \text { Edmodo } \\
\text { - Twitter } \\
\end{array}$ \\
\hline & Redes laborales & $\begin{array}{ll} & \text { Docente.me: red para docentes } \\
\text { - } \quad \text { Linkedln: compartir el perfil profesional } & \text { Science Penguin: científicos e investigadores }\end{array}$ \\
\hline & $\begin{array}{l}\text { Comunidades de práctica } \\
\text { y aprendizaje }\end{array}$ & $\begin{array}{ll}\text { - } & \text { MediaWiki: escritura colaborativa } \\
& \text { TWiki } \\
\text { - } & \text { Elgg } \\
\text { - } & \text { WordPress } \\
& \text { PeopleAggregator }\end{array}$ \\
\hline
\end{tabular}




\begin{tabular}{|c|c|c|}
\hline Categoría & Subcategoría & Herramientas \\
\hline \multirow{8}{*}{ 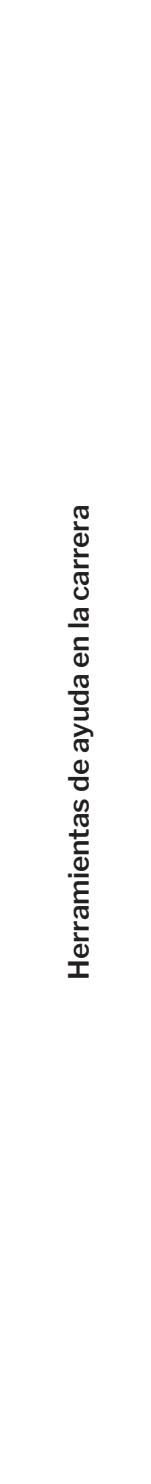 } & Matemáticas y estadística & $\begin{array}{ll}\text { - } & \text { Scientific Calculator: calculadora científica } \\
\text { - } & \text { Desmos graphing calculator: calculadora gráfica } \\
\text { - } & \text { Davitily Math Academy: problemas y ejercicios } \\
\text { - } & \text { GeoGebra: software libre de matemáticas } \\
\text { - } & \text { Fraction Calculator: calculadora de fracciones } \\
\text { - } & \text { Pytculador de las series de Fourier } \\
\text { - } & \text { Fórmulas de precálculo } \\
\text { - } \quad \text { Precálculo en web } \\
\text { - } \quad \text { Brilliant: ejercicios de matemáticas, física, etc. } \\
\text { - } \quad \text { Vitutor: ejercicicios y explicaciones de estadística }\end{array}$ \\
\hline & Física y química & $\begin{array}{ll}\text { - } & \text { Tabla periódica animada } \\
\text { - } & \text { Chemical Elements: tabla periódica con calcula- } \\
\text { - } & \text { Organic Sketchpad APK 1.1.0: sirve para crear } \\
& \text { compuestos } \\
\text { - } \quad \text { WebQC: se emplea para hacer balanceos en línea } \\
\text { - } \quad \text { Rincón didáctico de física y química de Educarex } \\
\text { - } \quad \text { Clases de física Walter Lewin, MIT } \\
\text { - } \quad \text { CE courses: sistemas de conversión de energía } \\
\quad \text { Length Conversion: conversor de longitud }\end{array}$ \\
\hline & Sistemas y electrónica & $\begin{array}{l}\text { - } \quad \text { Programamos: aprender a programar } \\
\text { - } \quad \text { Treehouse: diseño web, CSS, desarrollo de aplica- } \\
\text { - } \quad \text { GitHub es una comunidad de desarrolladores } \\
\text { - } \quad \text { Codecademy: programación de código HTML } \\
\text { - } \quad \text { CircuitzitLab: circuitos eléctricos } \\
\text { - } \quad \text { LogicLab: simulación de sistemas neumáticos }\end{array}$ \\
\hline & Idiomas & $\begin{array}{l}\text { - Google Traductor: traductor de idiomas Busuu: } \\
\text { comunidad en línea para aprender idiomas } \\
\text { - Duolingo: cursos de idiomas gratis }\end{array}$ \\
\hline & Educación & $\begin{array}{l}\text { - Didactalia: biblioteca de recursos educativos para } \\
\text { - } \quad \text { la primera infancia } \\
\text { Leer: fortalecer la lectura infantil }\end{array}$ \\
\hline & Geografía e historia & $\begin{array}{ll}\text { - } & \text { Alternative Geography } \\
\text { - } & \text { TimeMaps } \\
\text { - } & \text { Historical World Atlas } \\
\text { OpenLayers: mapas libres en la red }\end{array}$ \\
\hline & Finanzas y economía & $\begin{array}{ll}\text { - } & \text { Herramientas para las finanzas } \\
\text { - } \quad \text { Calculadora financiera } \\
\text { - } \quad \text { Readculador de amortización } \\
\quad \text { FerZero }\end{array}$ \\
\hline & Contabilidad & - ElsaMaraContable: canal de contabilidad \\
\hline \multirow{2}{*}{ 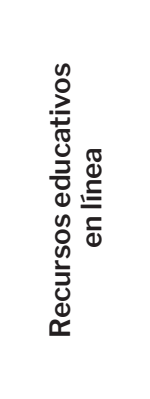 } & Portales de recursos educativos & $\begin{array}{ll}\text { - } & \text { Khan Academy: clases virtuales } \\
\text { - } & \text { Udemy: sitio en línea de cursos } \\
\text { - } & \text { MITxatina: recursos académicos } \\
\text { - } & \text { MIT - edX: cursos en línea del MIT } \\
\text { - } & \text { Mejorandola: portal de cursos gratuitos }\end{array}$ \\
\hline & Canales de videos educativos & $\begin{array}{ll}\text { - } & \text { YouTube Edu } \\
\text { - } & \text { YouTube para profesores } \\
\text { - } & \text { TeacherTube } \\
\text { - } & \text { Educatube } \\
\text { - } \quad \text { Canal de videos de la Universidad de Berkeley } \\
\text { - } & \text { El canal de Stanford en YouTube }\end{array}$ \\
\hline
\end{tabular}




\begin{tabular}{|c|c|c|}
\hline \multirow{4}{*}{ 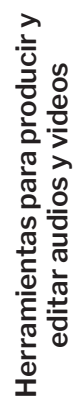 } & Grabación de videos & $\begin{array}{ll}\text { - } & \text { Debut Video Capture } \\
\text { - } & \text { SMRecorder } \\
\text { - } & \text { CamStudio } \\
& \text { ScreenFaceCam }\end{array}$ \\
\hline & Grabación de podcast & $\begin{array}{ll}\text { - } & \text { RSS Buddy: compatibles con iTunes y RSS } \\
\text { - } & \text { Audio Hijack Pro } \\
\text { - } & \text { Podbean } \\
\text { - } & \text { SodOmatic } \\
\end{array}$ \\
\hline & Edición de video & $\begin{array}{l}\text { - WeVideo }: \text { Pixorial } \\
\text { - Weavly } \text { - Wideo }\end{array}$ \\
\hline & Edición de audio & - Audacity: gratuito y de código abierto \\
\hline \multirow{13}{*}{ 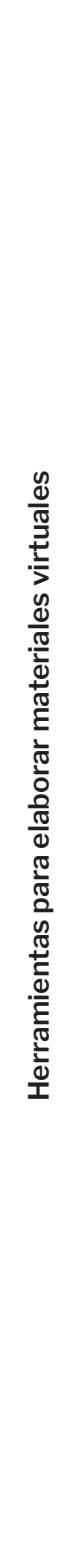 } & Editor de imágenes & $\begin{array}{ll}\text { - } & \text { Fotoeditor en línea } \\
& \text { GIMP }\end{array}$ \\
\hline & Elaborar videodiapositivas & $\begin{array}{ll}\text { - } & \text { SlideRocket } \\
\text { - } & \text { Knovio }\end{array}$ \\
\hline & Elaborar fotorrelatos & - $\quad$ PhotoPeach \\
\hline & Tablero digital & - Educreations: para iPad y PC \\
\hline & Elaborar infografías & $\begin{array}{ll}\text { - } & \text { Easel.ly: ofrece plantillas prediseñadas } \\
\text { - } & \text { Piktochart: editor de imágenes para infografías } \\
\text { - } & \text { Infogram:ly } \\
\text { - } & \text { GeoCommons: inforgrafías de mapas } \\
\text { - } & \text { FluxVFX: infografía en after efects } \\
\end{array}$ \\
\hline & Gráfico interactivo & - $\quad$ Thinglink \\
\hline & Elaborar libros interactivos & $\begin{array}{ll}\text { - } & \text { LIM y EdiLIM } \\
\text { - } & \text { Myebook } \\
\text { - } & \text { Zalaméo: convertir un PDF en un e-book } \\
\text { - } & \text { Booktrack Studio } \\
\text { - } & \text { MyScrapbook interactivos en 3D } \\
\end{array}$ \\
\hline & Cómics & $\begin{array}{l}\text { - } \quad \text { Pixton } \\
\text { - Make Beliefs Comix } \\
\text { - MiTYH: comic para mitos, cuentos y leyendas }\end{array}$ \\
\hline & Avatares animados & $\begin{array}{ll}\text { - } & \text { Xtranormal } \\
\text { - } & \text { Second Life } \\
\text { - } & \text { Sloodle: Second Life para Moodle } \\
\text { - } \quad \text { GoAnimate }\end{array}$ \\
\hline & Encuestas y pruebas evaluativas & $\begin{array}{l}\text { - } \quad \text { Gnowledge: crear y publicar pruebas evaluativas } \\
\text { - SurveyMonkey: para hacer encuestas }\end{array}$ \\
\hline & Juegos educativos & 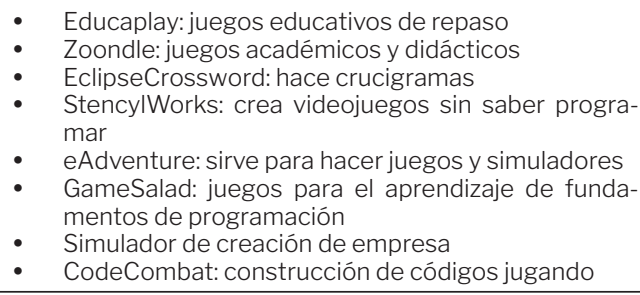 \\
\hline & $\begin{array}{l}\text { Herramientas para hacer objetos } \\
\text { de aprendizaje completos }\end{array}$ & $\begin{array}{ll}\text { - } & \text { MyDocumenta } \\
\text { - } & \text { CUadernia } \\
\text { - } \quad \text { LAMSTRUCTOR } & \text { Maborar actividades colaborativas } \\
\text { - } & \text { Malted: crear contenidos para idiomas }\end{array}$ \\
\hline & Listas de software & $\begin{array}{l}\text { - } \quad \text { Listas de software libre } \\
\text { - } \quad \text { Software libre educativo } \\
\text { - } \quad \text { Software educativo para Linux }\end{array}$ \\
\hline
\end{tabular}

Fuente: Elaboración propia. 
Comunicación, redes, aprendizaje y desarrollo institucional y social

\section{Implementación de la caja de herramientas}

Existen en la web más de 80000 aplicaciones educativas, la mayoría gratuitas, entonces el dilema no es escoger una herramienta que se aplique en el aprendizaje, sino saber cuál es la más apropiada para incluirla en la caja; esta búsqueda y descarte duró casi dos años para generar la primera versión de ella.

Con las herramientas seleccionadas, se organizó una cuenta en wordpress donde se enlazaban según las categorías. Cada página tiene la herramienta, más una descripción de ella, un enlace para acceder a la herramienta y un video tutorial insertado en código HTML para manejarla.

Después, un grupo de ingenieros creó una página web con el menú principal que conduce a cada una de las categorías y de la ella a cada una de las herramientas.

Se hicieron algunos videos explicativos de la caja y se abrió un portal de opinión de los estudiantes; más adelante se hará un análisis de las precepciones que se publicaron. La página web de la caja de herramientas es http://caja.poligran.edu.co/.

Figura 7.7. Interior de las categorías de la caja de herramientas

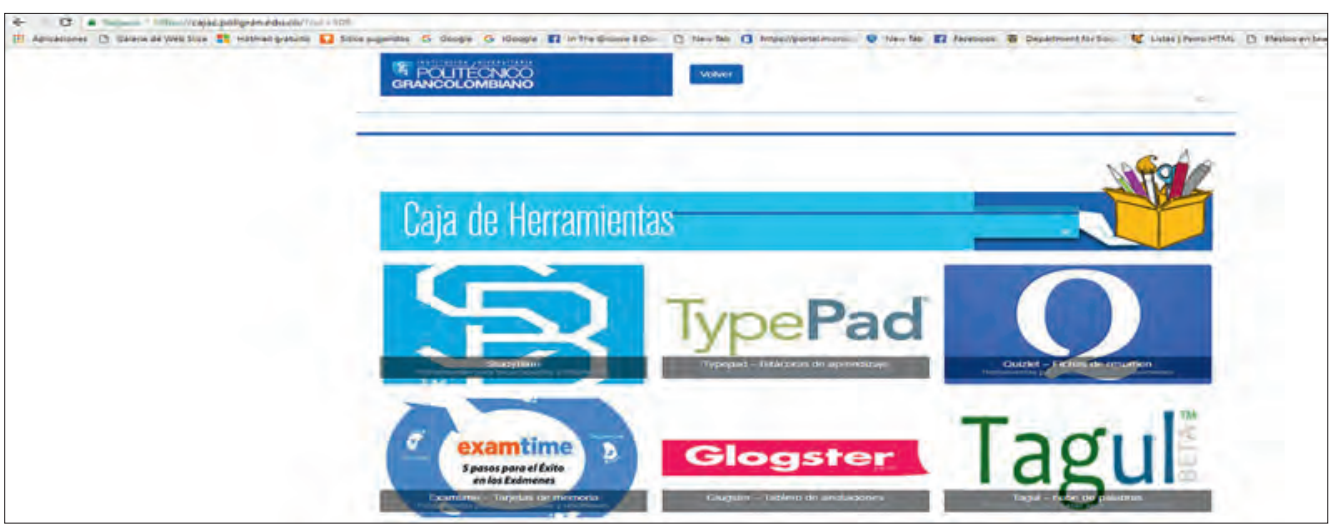

Fuente: http://caja.poligran.edu.co/

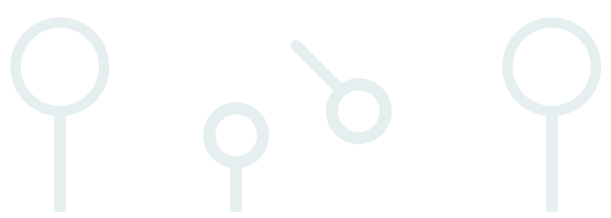




\section{Resultados}

\section{Punto de partida}

A continuación, se muestran los resultados estadísticos de la encuesta de percepción de los estudiantes sobre el punto de partida. Se tomó una población de 183 estudiantes al azar entre quienes lo cursaron.

\section{Tabla 7.2. Encuesta de satisfacción a los estudiantes del punto de partida}

1. ¿El módulo fue útil para conocer la ruta de bienvenida, el manejo del aula y el campus virtual?

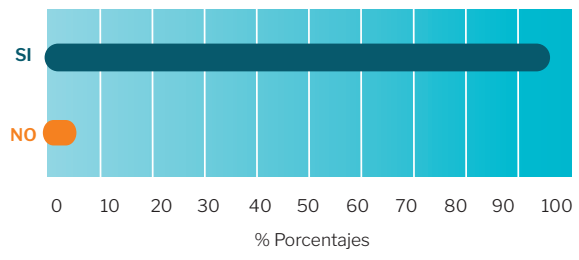

Sī $95.8 \%$

No $4.92 \%$

3. ¿El módulo le ayudó para iniciar un proceso de lectura?

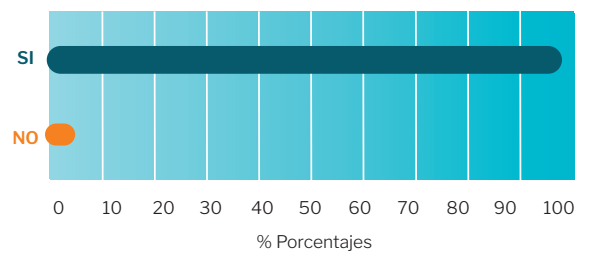

Sī $96.15 \%$

No $3.85 \%$
2. ¿El módulo le permitió replantear sus hábitos de estudio?

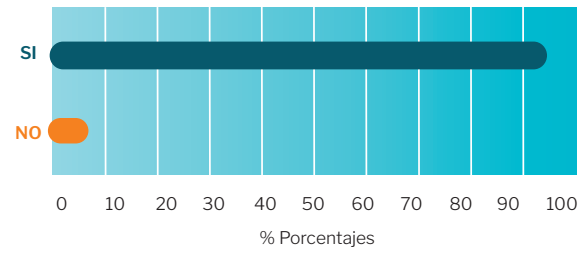

Sī $94.54 \%$

No $5.46 \%$

4. ¿El módulo le ayudó para generar una conciencia en el manejo del tiempo como estudiante virtual?

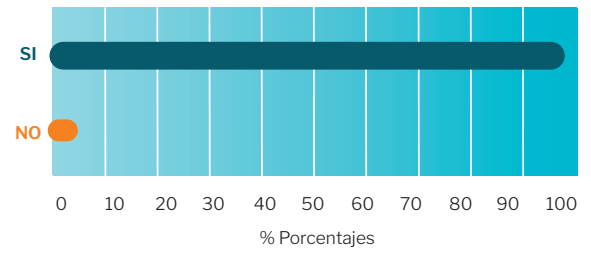

Sī $97.27 \%$

No $2.73 \%$ 
5. ¿Cree que está listo para la virtualidad?

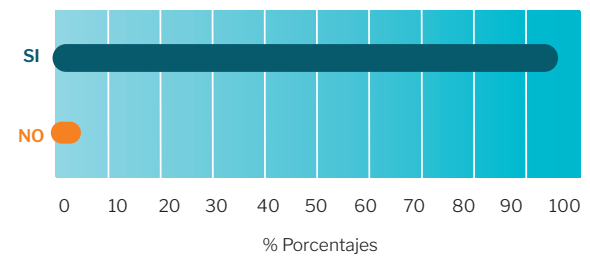

Sī $93.99 \%$

No $6.01 \%$

Fuente: Elaboración propia.

Esta fue la última pregunta de la encuesta, consistente en una autoevaluación del desempeño de los diferentes estudiantes:

De 1 a 5 evalúe su desempeño en el punto de partida.

Tabla 7.3. Resultados de la autoevaluación de los estudiantes que cursaron el punto de partida

\begin{tabular}{|c|c|c|c|c|c|c|}
\hline $\mathbf{1}$ & $\mathbf{2}$ & $\mathbf{3}$ & $\mathbf{4}$ & $\mathbf{5}$ & Total & Promedio \\
\hline $1.09 \%$ & $3.83 \%$ & $21.86 \%$ & $49.73 \%$ & $23.50 \%$ & \multirow{2}{*}{183} & 3.91 \\
\cline { 1 - 5 } \cline { 4 - 6 } & 7 & 40 & 91 & 43 & & \\
\hline
\end{tabular}

Fuente: Elaboración propia.

De acuerdo con los resultados, los estudiantes tienen una excelente percepción del AVA para iniciar su proceso en la virtualidad. Sin embargo, es prioritario que el ambiente esté sintonizado con las pruebas de caracterización para no verificar solo su acción motivadora, sino también su acción educativa para iniciar por parte del estudiante su proceso formal de aprendizaje, ya que el fin primordial del ambiente es facilitar el afianzamiento a la modalidad virtual. Estos resultados son de percepción del estudiante, por lo cual no son concluyentes; para ello, se requiere una investigación posterior que evalúe cómo mejora la adaptación de aquel a la virtualidad por medio del AVA. 


\section{Caja de herramientas}

Para la caja de herramientas, se creó un espacio de opinión de los estudiantes, allí los estudiantes dejaban sus percepciones acerca de la misma. A continuación, en la tabla 7.4, se presentan algunos comentarios de los estudiantes consignados en el espacio de opinión. Por cuestiones de transparencia, se dejaron las intervenciones sin edición alguna.

Tabla 7.4. Comentarios de los estudiantes del Politécnico Grancolombiano sobre la publicación de la caja de herramientas

\begin{tabular}{|c|c|c|}
\hline Estudiante & $\begin{array}{l}\text { Fecha de } \\
\text { publicación }\end{array}$ & Comentario \\
\hline $\begin{array}{l}\text { Diana Soraya } \\
\text { Escobar Cárdenas }\end{array}$ & $\begin{array}{l}16 \text { abril, } \\
2015 \text { at } \\
4: 40 \text { pm }\end{array}$ & $\begin{array}{l}\text { Felicitaciones Peligran! esto es exactamente lo que necesitába- } \\
\text { mos sobre todo los estudiantes de la modalidad virtual. } \\
\text { Muchas gracias por pensar en nosotros! Excelente! }\end{array}$ \\
\hline Elizabeth Piragauta & $\begin{array}{l}16 \text { abril, } \\
2015 \text { at } \\
6: 15 \mathrm{pm}\end{array}$ & $\begin{array}{l}\text { Súper es indispensable para los estudiantes de virtual poli gra- } \\
\text { cias....=) }\end{array}$ \\
\hline Magnolia Henao & $\begin{array}{l}17 \text { abril, } \\
2015 \text { at } \\
2: 28 \mathrm{pm}\end{array}$ & $\begin{array}{l}\text { Necesario para todos los estudiantes, muy buena herramienta. } \\
\text { Gracias por pensar en nosotros!!! }\end{array}$ \\
\hline $\begin{array}{l}\text { Andrea del Pilar } \\
\text { Méndez Uscategui }\end{array}$ & $\begin{array}{l}17 \text { abril, } \\
2015 \text { at } \\
7: 47 \mathrm{pm}\end{array}$ & $\begin{array}{l}\text { Me parece muy interesante esta caja de herramientas pues es } \\
\text { para ayuda de nosotros mismos como estudiantes tanto de pre- } \\
\text { sencial como de virtual, gracias por esta gran propuesta. }\end{array}$ \\
\hline $\begin{array}{l}\text { Maritza Castellanos } \\
\text { Sarmiento }\end{array}$ & $\begin{array}{l}18 \text { abril, } \\
2015 \text { at } \\
7: 29 \text { am }\end{array}$ & $\begin{array}{l}\text { Es una herramienta que será muy útil en la medida en que poda- } \\
\text { mos aprovecharla. Gracias por trabajar por el bien de la familia } \\
\text { del Poli. }\end{array}$ \\
\hline $\begin{array}{l}\text { Álvaro José } \\
\text { Galvis G. }\end{array}$ & $\begin{array}{l}18 \text { abril, } \\
2015 \text { at } \\
9: 57 \text { am }\end{array}$ & $\begin{array}{l}\text { Buenos días, gracias poli me parece muy buen apoyo la caja de } \\
\text { herramientas. saludos a todos Âlvaro José }\end{array}$ \\
\hline Carlos Florián & $\begin{array}{l}18 \text { abril, } \\
2015 \text { at } \\
12: 34 \text { pm }\end{array}$ & $\begin{array}{l}\text { Cordial Saludo Sr. Trujillo, gracias por su ánimo de innovar y facili- } \\
\text { tar nuestro autoaprendizaje. }\end{array}$ \\
\hline $\begin{array}{l}\text { Javier Andrés } \\
\text { Ramírez Cruz }\end{array}$ & $\begin{array}{l}18 \text { abril, } \\
2015 \text { at } \\
3: 28 \mathrm{pm}\end{array}$ & $\begin{array}{l}\text { Felicitaciones a todo el equipo de docentes y colaboradores del } \\
\text { politécnico, ya que con todos estos nuevos proyectos piensan } \\
\text { más en nosotros los estudiantes donde nos facilitan y nos van } \\
\text { guiando en nuestro proceso académico }\end{array}$ \\
\hline Jon Triana & $\begin{array}{l}18 \text { abril, } \\
2015 \text { at } \\
7: 34 \mathrm{pm}\end{array}$ & $\begin{array}{l}\text { Sugiero que le pongan links de Me gusta para publicarlos en las } \\
\text { diferentes redes sociales. Muy bueno!!! }\end{array}$ \\
\hline $\begin{array}{l}\text { Edilberto } \\
\text { Santana Cortes }\end{array}$ & $\begin{array}{l}18 \text { abril, } \\
2015 \text { at } \\
10: 13 \mathrm{pm}\end{array}$ & $\begin{array}{l}\text { Saludos para toda la comunidad del Poli......excelentes herra- } \\
\text { mientas, } \\
\text { muy prácticas y muy acertadas para facilitar los compromisos } \\
\text { académicos. } \\
\text { Mil gracias por ayudarnos a cumplir los objetivos }\end{array}$ \\
\hline
\end{tabular}

Fuente: Elaboración propia. 
Si bien la percepción de los estudiantes es buena, la utilización de la caja de herramientas adquiere otras dimensiones si se le da una aplicabilidad desde el aula. Sin embargo, estas opiniones tampoco son concluyentes, porque no es una muestra significativa, por tanto, se requiere una investigación posterior que indague sobre el impacto en el proceso del estudiante con el uso de las herramientas que encuentran en la caja; asimismo, hace falta una investigación más profunda sobre el uso que le dan los estudiantes a la caja.

El uso de la caja se refuerza desde los tres módulos (Técnicas para el aprendizaje autónomo, Herramientas para la productividad y Matemáticas), porque en ellos el estudiante encuentra actividades que lo obligan a usarlas. Por ejemplo, uno de los temas en aprendizaje autónomo es el resumen de la información a través de los mapas mentales y conceptuales, entonces el tutor desde el aula lo orienta para que ingrese a la caja y alli emplee las herramientas especiales para hacer mapas mentales y conceptuales.

En la categoría Herramientas de ayuda en la carrera, algunos tutores del área de finanzas solicitaron que les implementaran dos herramientas: una de simulación pensional y la otra una calculadora financiera hecha por ellos. De esa manera, el tutor puede integrar lo que están viendo en el aula con otros contextos virtuales. Esta práctica debe ampliarse a todas las facultades y departamentos académicos, de esa manera se cumple el propósito de la caja que es prestarle una ayuda al estudiante y facilitarle la gestión en el aula.

\section{Conclusiones}

Es fundamental como estrategia de permanencia hacer un entrenamiento adecuado de adaptación a la modalidad, que no es solo una introspección en el manejo de una herramienta para gestionar el proceso académico, sino una transformación de la forma como se percibe la virtualidad y cómo esta se transforma con un mayor compromiso del estudiante.

De igual manera, es muy importante realizar pruebas de caracterización que permitan hacer un diagnóstico de cómo llegan los estudiantes, y así se pueden planear otras estrategias de acompañamiento y de refuerzo, y comparar si tales estrategias surten efecto en la comunidad educativa en sus resultados o mejoras.

Las dos estrategias contaron con el beneplácito en la comunidad estudiantil. El punto de partida fue aceptado y los estudiantes lo sienten importante en su proceso de iniciación en la virtualidad, lo cual redunda en permanencia, motivación y gusto por la modalidad. La caja de herramientas ha sido muy útil para la vida académica de los estudiantes, que se implementó para estudiantes nuevos y antiguos, con muy buenos resultados. Sin embargo, vale la pena profundizar en los efectos producidos en ellos con las dos estrategias. 
La implementación de la caja de herramientas continúa, la finalidad es integrar estudiantes y tutores para que se haga un trabajo mancomunado en la inserción de nuevas herramientas que aumenten la eficiencia en las labores académicas. Luego, continúa la etapa de trabajo con las áreas académicas para proponer herramientas propias de cada programa académico.

Son muchas las estrategias que se pueden implementar para disminuir los niveles de deserción en el Politécnico Gran colombiano. En este momento, además de las dos estrategias explicadas, se está desarrollando una aplicación de software denominado GIPEV (Gestión de la Información para Educación Virtual) que analiza y ayuda a la gestión de los estudiantes que no ingresan a las aulas o que presentan bajos resultados para crear un sistema de alarmas tempranas que permitan hacer acompañamiento y asesoría a aquellos. Esto nos lleva a la gran conclusión de este capítulo: cualquier estrategia que se implemente en beneficio de la permanencia repercutirá de manera positiva en nuestros estudiantes, quienes tendrán más servicios y una vida académica de mejor y mayor calidad.

\section{Referencias}

Attwell, G. (2007). Personal Learning Environments-the fututre of eLearning?, eLearning Papers, 2(1), pp. 1-7. Recuperado en: http://citeseerx.ist.psu.edu/viewdoc/download?doi=10.1.1.97.3011\&rep=rep1\&type=pdf

Aula.virtual.ucv.cl (2012). ¿Qué son los entornos personales de aprendizaje? Recuperado de http://aula.virtual.ucv.cl/wordpress/entornos-personales-de-aprendizaje-como-sistemas-de-gestion/

Bruner, J. S. (ed.) (1980). Investigaciones sobre el desarrollo cognitivo. Madrid: Pablo del Río. Castañeda, L. y Adell, J. (eds.) (2013). Entornos personales de aprendizaje: claves para el ecosistema educativo en red. Alcoy: Marfil. Recuperado de http://www.um.es/ple/libro/

Hederich, C. y Camargo, A. (2000). Estilo cognitivo y logro en el sistema educativo de la ciudad de Bogotá. Bogotá: Instituto para la Investigación Educativa y el Desarrollo Pedagógico.

Icfes (Instituto Colombiano para la Evaluación de la Educación) (2013). Sistema Nacional de Evaluación Estandarizada de la Educación: Alineación del examen SABER 11². Bogotá: Icfes. Recuperado de https://goo.gl/pf7nuu

López Vargas, O. y Triana Vera, S. (2013). Efecto de un activador computacional de autoeficacia sobre el logro de aprendizaje en estudiantes de diferente estilo cognitivo. Revista Colombiana de Educación, 64, 225-244.

Melero Abadía, P. (2000). Métodos y enfoques en la enseñanza-aprendizaje del español como lengua extranjera. Madrid: Edelsa. 
Comunicación, redes, aprendizaje y desarrollo institucional y social

Poy, R. y Gonzales-Aguilar, A. (2014). Factores de éxito de los MOOC: algunas consideraciones críticas. RISTI: Revista Ibérica de Sistemas e Tecnologias de Informação, 1, 105-118.

Santamaría González, F. (2010). Ecosistemas digitales en entornos de aprendizaje. Buenos Aires: virtual Educa. Recuperado de https://es.slideshare.net/lernys/ecosistemas-digitales-en-entornos-de-aprendizaje

Siemens, G. (2004). Connectivism: A learning theory for the digital age. Recuperado de http://www.elearnspace.org/Articles/connectivism.htm

Torres Pedroza, M. C. (2013). Desarrollo de habilidades de aprendizaje autorregulado en un escenario de aprendizaje basado en problemas en estudiantes de la Facultad de Medicina de la Fundación Universitaria Sanitas (Tesis de maestría, Universidad de La Sabana, Bogotá, Colombia). Recuperado de https://intellectum.unisabana.edu.co/handle/10818/9394

Uoctic-grupo6.wikispaces.com (s. f.). El conectivismo, una teoría para la era digital. Recuperado de http://uoctic-grupo6.wikispaces.com/Conectivismo

Varón Rondón, G. L. y Moreno Angarita, M. (2009). La escritura académica y los ambientes virtuales de aprendizaje en la educación superior. Bogotá: Universidad Nacional de Colombia. 